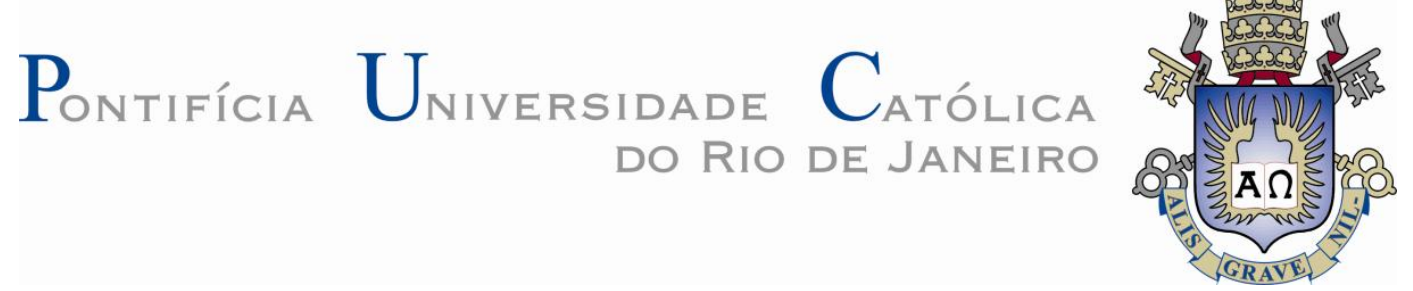

Cristiano Maroja de Medeiros

\title{
Avaliação de Desempenho de Fundos de \\ Previdência Renda Fixa
}

Dissertação de Mestrado

Dissertação apresentada ao Programa de Pós-Graduação em Administração de Empresas da PUC-Rio como requisito parcial para a obtenção do título de Mestre em Administração de Empresas.

Orientador: Prof. André Luiz Carvalhal da Silva 


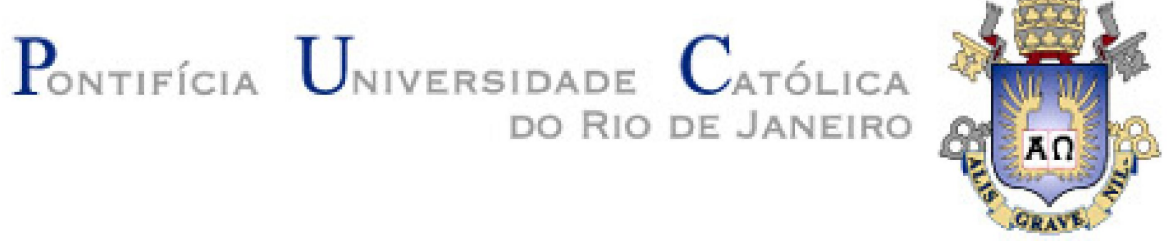

Cristiano Maroja de Medeiros

\title{
Avaliação de Desempenho de Fundos de \\ Previdência Renda Fixa
}

Dissertação apresentada como requisito parcial para obtenção do grau de Mestre pelo Programa de PósGraduação em Administração de Empresas da PUC-Rio. Aprovada pela Comissão Examinadora abaixo assinada.

\author{
Prof. Andre Luiz Carvalhal da Silva \\ Orientador \\ Departamento de Administração - PUC-Rio
}

Prof. Luiz Felipe Jacques da Motta Departamento de Administração - PUC-Rio

Prof. Gustavo Silva Araujo

Banco Central

Profa. Mônica Herz

Vice-Decana de Pós-Graduação do CCS - PUC-Rio

Rio de Janeiro, 07 de abril de 2015 
Todos os direitos reservados. É proibida a reprodução total ou parcial do trabalho sem autorização da universidade, do autor e do orientador.

\section{Cristiano Maroja de Medeiros}

Graduou-se em Engenharia de Produção na Universidade Federal do Rio de Janeiro em 1998. Cursou pós graduação em Economia Empresarial na Universidade Cândido Mendes em 2000. De 1994 a 2011 atuou em instituições financeiras como o Banco BBM e Banco CR2.

Ficha Catalográfica

Medeiros, Cristiano Maroja de

Avaliação de desempenho de fundos de previdência renda fixa / Cristiano Maroja de Medeiros ; orientador: André Luiz Carvalhal da Silva. -2015.

62 f. : il. (color.) ; $30 \mathrm{~cm}$

Dissertação (mestrado)-Pontifícia Universidade Católica do Rio de Janeiro, Departamento de Administração, 2015.

Inclui bibliografia

1. Administração - Teses. 2. Análise de desempenho. 3. Fundos de investimento. 4. Previdência. 5. Renda fixa. I. Silva, André Luiz Carvalhal da. II. Pontifícia Universidade Católica do Rio de Janeiro. Departamento de Administração. III. Título.

CDD: 658 


\section{Agradecimentos}

Ao meu orientador Professor André Luiz Carvalhal da Silva, por aceitar a minha orientação tardia.

Ao CNPq e à PUC-Rio, pelos auxílios concedidos, sem os quais este trabalho não

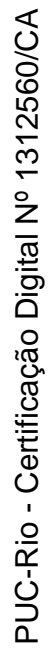
poderia ter sido realizado.

Aos meus filhos e, em especial, à minha esposa Flavia por serem fonte de amor e motivação.

Ao meu pai, Carlos, por ser um exemplo de trabalho.

À minha mãe, Flavia, pelo exemplo de luta e superação.

Aos meus colegas da PUC-Rio.

Aos professores que participaram da Comissão Examinadora.

A todos os professores e funcionários do Departamento pelos ensinamentos e pela ajuda.

A todos os amigos e familiares que de uma forma ou de outra contribuíram para o êxito do meu trabalho. 


\section{Resumo}

Medeiros, Cristiano Maroja de; Silva, André Luiz Carvalhal da. Avaliação de desempenho de fundos de previdência renda fixa. Rio de Janeiro, 2015. 62p. Dissertação de Mestrado - Departamento de Administração, Pontifícia Universidade Católica do Rio de Janeiro.

Esse trabalho procura verificar como se comportaram os fundos de Previdência Renda Fixa no Brasil, no período de 2003 a 2014. A amostra utilizada nesta pesquisa corresponde a 382 fundos, que representam aproximadamente $99 \%$ do total de recursos investidos em fundos de previdência de renda fixa. $\mathrm{O}$ intuito da pesquisa foi (i) analisar o comportamento dos fundos da categoria e observar se possuem capacidade satisfatória de desempenho, (ii) ampliar tal análise para um grupo segregado de fundos selecionados pela característica de isenção de cobrança de taxas, nomeados como Fundos Master, (iii) avaliar se existe diferença de gestão entre gestores nacionais e estrangeiros e, (iv) investigar a possibilidade de criação de um índice benchmark para o setor, com o intuito de facilitar a avaliação por parte do investidor ao longo do investimento. Os resultados indicaram, através do estudo do Índice de Sharpe Histórico, que os fundos de Previdência Renda Fixa, no período analisado, não conseguiram atingir um resultado satisfatório. Entretanto, o grupo de Fundos Master conseguiu uma performance superior aos da categoria, obtendo também um excesso de retorno com significância estatística de 5\%. Em relação ao comparativo entre gestores nacionais e estrangeiros, não se pode afirmar que existe diferença significativa entre eles. Os resultados ainda concluíram que o coeficiente relativo ao CDI é extremamente relevante, demonstrando o seu uso como único benchmark.

\section{Palavras-chave}

Análise de Desempenho; Fundos de Investimento; Previdência; Renda Fixa. 


\section{Abstract}

Medeiros, Cristiano Maroja de; Silva, André Luiz Carvalhal da (Advisor). Performance Evaluation of Fixed Income Pension Funds. Rio de Janeiro, 2015. 62p. MSc. Dissertation - Departamento de Administração, Pontifícia Universidade Católica do Rio de Janeiro.

This dissertation analyses the performance of the Brazilian Fixed Income Pension funds, from 2003 to 2014. The sample used in this study corresponds to 382 funds, representing approximately $99 \%$ of total assets in fixed income pension funds industry. The aim of the study was (i) to analyze the behavior of such category of funds and observe if they have satisfactory performance capacity, (ii) extend this analysis to a segregated group of selected funds by the characteristic of charging fees exemption, named Master Funds (iii) assess whether there are differences in management between brazilian and foreign managers, and (iv) investigate the possibility of creating a benchmark index for the sector in order to facilitate the assessment by the investor during the investment decision. The results indicated, considering Historical Sharpe ratio, that the Fixed Income Pension funds failed to achieve a satisfactory result. However, the Master Fund group achieved a superior performance to the category, also getting an excess return with statistical significance of $5 \%$. Regarding the comparison between domestic and foreign managers, we cannot say that there is significant difference between them. The results also found that the relative ratio to $\mathrm{CDI}$ is highly relevant, demonstrating its use as a unique benchmark.

\section{Keywords}

Performance Evaluation; Mutual Funds; Retirement; Fixed Income; Pension. 


\section{Sumário}

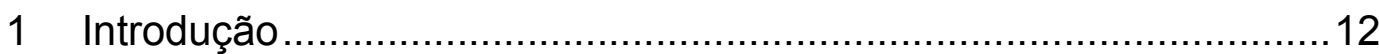

2 Sistema de Previdência Complementar................................... 16

3 Revisão de Literatura........................................................22

3.1 Literatura sobre Análise de Desempenho de Fundos de Previdência e Fundos de Investimentos .......................................22

3.1.1 Fundos de Previdência......................................................... 22

3.1.2 Fundos de Investimentos ................................................. 23

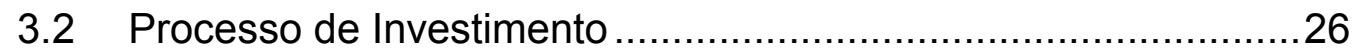

3.3 As Principais Medidas de Desempenho...............................29

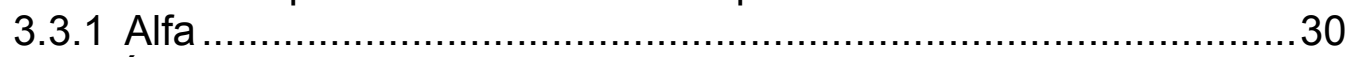

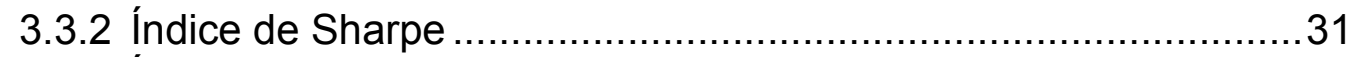

3.3.3 Índice de Treynor ...................................................... 33

3.3.4 Medida Ômega............................................................ 33

3.3.5 Medida de Retorno Ajustado ao Risco do Morningstar ............... 34

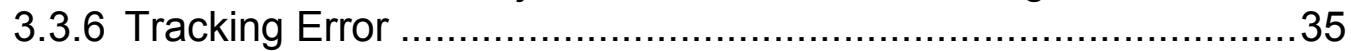

3.4 Análise de Estilo Baseada em Retornos. ................................36

$4 \quad$ Dados e Metodologia .................................................... 38

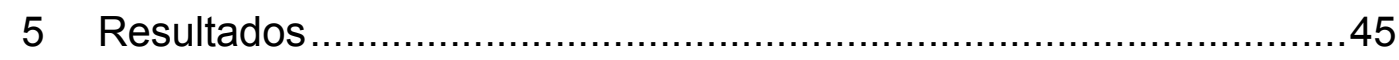

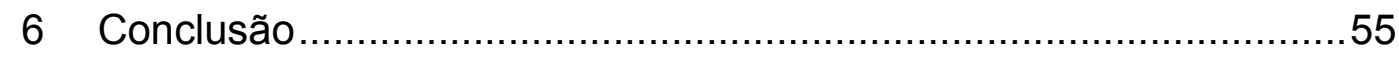

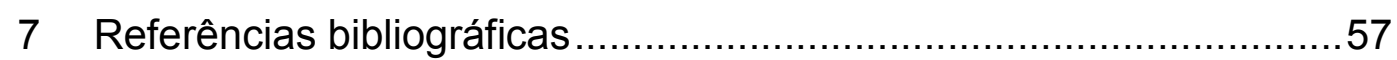




\section{Lista de figuras}

Figura 1- Modalidade dos planos de EFPC. Evolução percentual...........18

Figura 2 - Distribuição da receita por produto.................................. 19

Figura 3 - Evolução da carteira de investimento por produto. .................20

Figura 4 - Composição da dívida pública federal por indexador -

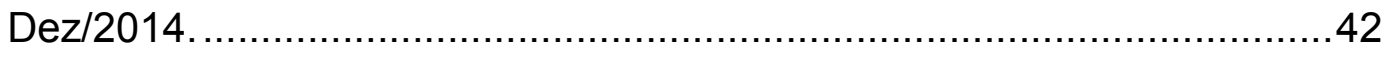

Figura 5 - Estoque de títulos privados por indexador. ........................ 42

Figura 6 - Índice de Sharpe Histórico dos Fundos de Investimento. .......51

Figura 7 - Índice de Sharpe Histórico dos Fundos Master......................51

Figura 8 - Índice de Sharpe Histórico dos Fundos Ex Master..................52

Figura 9 - Resumo de Teste de Hipótese de Wilcoxon. ........................53 


\section{Lista de tabelas}

Tabela 1 - Ativo Total dos planos EFPC - Segundo modalidade ...........17

Tabela 2 - Distribuição de fundos por gestor ....................................40

Tabela 3 - Estatística Descritiva das Amostras de Retornos .................46

Tabela 4 - Análise de Estilo Baseada em Retornos - Principais Gestores 


\section{Lista de quadros}

Quadro 1 - Resumo do modelo de um fator - CDI..............................49

Quadro 2 - Coeficientes do modelo de um fator - CDI ..........................49 49

Quadro 3 - Resumo do modelo de três fatores - CDI, IRF-M e IMA-B ...49

Quadro 4 - Coeficientes do modelo de três fatores - CDI, IRF-M e IMA-B

Quadro 5 - Teste de Kolmogorov-Smirnov para a série de diferenças de retorno vs CDI 


\section{Siglas}

ANBIMA - Associação Brasileira das Entidades dos Mercados Financeiro e de Capitais

BC - Banco Central do Brasil

CETIP - Central de Custódia e Liquidação Financeira de Títulos Privados

CMN - Conselho Monetário Nacional

CNPC - Conselho Nacional de Previdência Complementar

CNSP - Conselho Nacional de Seguros Privados

CVM - Comissão de Valores Mobiliários

D. L. - Decreto Lei

EAPC - Entidades Abertas de Previdência Complementar

E. C. - Emenda Constitucional

EFPC - Entidades Fechadas de Previdência Complementar

FENAPREVI - Federação Nacional de Previdência Privada e Vida

FIE - Fundo de Investimento Especialmente Constituído

IAPC - Institutos de Aposentadoria e Pensões dos Comerciários

INPS - Instituto Nacional de Previdência Social

ITCMD - Imposto de Transmissão Causa Mortis e Doação

L. C. - Lei Complementar

MPAS - Ministério da Previdência e Assistência Social

PREVIC - Superintendência Nacional de Previdência Complementar

PGBL - Plano Gerador de Benefício Livre

STN - Secretaria do Tesouro Nacional

SUSEP - Superintendência de Seguros Privados

VGBL - Vida Gerador de Benefício Livre 


\section{1 \\ Introdução}

O envelhecimento da população economicamente ativa, sem o respectivo crescimento vegetativo para suprir e equilibrar a necessidade das receitas da previdência no sistema brasileiro, que possui sua estrutura básica baseada na contribuição dos ativos para pagamento dos inativos, estimula os cidadãos a desacreditarem no sistema da previdência pública.

Dentro deste contexto, os cidadãos, cada vez mais, vêm procurando por opções de instrumentos de proteção e manutenção dos recursos para o período da aposentadoria, tal como a previdência privada complementar. A previdência complementar no Brasil surgiu, de forma regulamentar, com a lei nº 6.435 , de 1977 através de algumas entidades de previdência privada ligadas ao setor estatal, pela administração de planos de aposentadoria na modalidade de benefício definido em que se tem o risco atuarial. Evoluiu, durante a década de 80 e 90, para as empresas privadas e para os planos de contribuição definida e mistos, nos quais esses riscos foram mitigados.

Somente com o advento das leis complementares $\mathrm{n}^{\mathrm{o}} \mathrm{s} 108$ e 109, em 2001, que a previdência complementar ganhou novo impulso, alinhada às práticas internacionais, em termos de novos instrumentos, novos tipos de entidade de previdência complementar, transparência, gestão financeira e aperfeiçoamento na governança.

O sistema teve, a partir dessas leis, e principalmente depois de 2003, um revigoramento com a regulamentação, como: (i) a portabilidade dos recursos, (ii) a extensão da proteção previdenciária a outras categorias profissionais, como engenheiros, dentistas, médicos, comerciários, magistrados, procuradores e advogados, e (iii) o novo regime tributário, que trouxe o diferimento fiscal na fase de capitalização de recursos além da regressividade, opcional, que combina alíquotas de imposto de renda com prazo de acumulação. 
Segundo a Anbima, em dezembro de 2014 os fundos abertos de previdência privada totalizavam aproximadamente $\mathrm{R} \$ 400$ bilhões de patrimônio, ou 15\% do total de recursos administrados de terceiros, apresentando o maior crescimento entre todos os fundos acompanhados pela Anbima. A categoria Previdência Renda Fixa respondia pela maioria dos recursos do setor de previdência ( $95 \%$ do total).

Atualmente existem poucos estudos publicados sobre tal categoria de fundos no Brasil. Diante de seu crescimento expressivo e do fato da mesma possuir característica não compulsória, vislumbrou-se uma oportunidade de exploração desse estudo como ferramenta de auxílio ao poupador na hora de direcionar seus recursos no Brasil.

Na prática, os planos de previdência privada complementar funcionam como fundos de investimentos e, devido à necessidade de geração de renda no período da aposentadoria, a sua avaliação de desempenho tem papel fundamental. A avaliação de desempenho de fundos de investimentos consiste, basicamente, em analisar os retornos e riscos em determinado período e seus comportamentos se comparado ao índice de referência (benchmark) determinado.

A Moderna Teoria de Finanças de Markowitz (1952) ${ }^{1}$, desenvolvida a partir da análise da média-variância, deu início ao estudo de vários conceitos de análise de desempenho, permitindo a avaliação do retorno incorporando o risco do ativo. Posteriormente, surgiram diversos trabalhos, como pesquisa científica, sobre o mesmo tema, dentre eles destacam-se os índices de Treynor (1965), Sharpe (1966), Jensen (1967) e Modigliani e Modigliani (1997) que têm sido amplamente utilizados na análise da indústria de fundos de investimento.

Esse trabalho procura verificar como se comportaram os fundos de Previdência Renda Fixa, no período de 2003 a 2014, utilizando-se as citadas metodologias de avaliação de desempenho consagradas na literatura. O objetivo da pesquisa é (i) analisar o comportamento dos fundos da categoria e observar se possuem capacidade satisfatória de desempenho, (ii) ampliar tal análise para um grupo segregado de fundo selecionados pela característica de isenção de cobrança de taxas, nomeados como Fundos Master $^{2}$, (iii) avaliar se existe diferença de gestão

\footnotetext{
${ }^{1} \mathrm{O}$ conceito introduzido por Markowitz fundamenta-se no princípio de mercados eficientes, compostos por agentes racionais, nos quais os preços refletem todas as informações relevantes e inexistem oportunidades de ganhos excepcionais.

${ }^{2}$ Fundos Master são fundos destinados a receber exclusivamente aplicações de outros fundos de investimento e onde não incidem taxas de administração e performance.
} 
entre gestores nacionais e estrangeiros e, (iv) investigar a possibilidade de criação de um índice benchmark para o setor, com o intuito de facilitar a avaliação por parte do investidor ao longo do investimento.

Para os referidos estudos, foram aplicados o modelo de avaliação de performance clássico de Sharpe (1966) e a Análise de Estilo Baseada em Retornos de Sharpe (1992). A coleta de dados foi realizada junto à CVM por meio de sua página na internet. Os testes estatísticos foram implementados com o auxílio do pacote estatístico SPSS versão 22 da IBM ${ }^{\circ}$.

Uma abordagem comum em tais estudos é empregar técnicas para avaliar o desempenho de fundos mútuos com uma carteira diversificada. Mas, como descrito acima, e devido a restrições da legislação dessa categoria, a metodologia utilizada neste estudo está relacionada com Blake, Elton e Gruber (1993) ao trabalhar com fundos de renda fixa.

Através do estudo do Índice de Sharpe Histórico os fundos de previdência renda fixa, no período analisado, não conseguiram atingir um resultado satisfatório. Entretanto, o grupo de Fundos Master conseguiu uma performance superior aos da categoria, obtendo também um excesso de retorno com significância estatística de $5 \%$. O interessante sobre o grupo de fundos Master é que apesar de pouco numeroso (são 38 fundos dentre uma amostra de 382) ele é responsável por cerca de $90 \%$ do volume de recursos do setor, lhe conferindo grande representatividade nos resultados.

Observa-se também, que a totalidade dos grandes gestores de fundos Master consegue obter um bom resultado na parte ativa das carteiras. Esse resultado excepcional contrasta com o obtido em diversos estudos do gênero. Uma explicação possível para o fenômeno anormal está associada ao fato de haver extrema concentração de recursos nas mãos de poucos gestores, lhes provendo um maior poder de barganha para composição de suas carteiras.

Segundo dados do setor compilados pelo Banco Central do Brasil, em setembro de 2014, o setor financeiro brasileiro é extremamente concentrado, com os 10 maiores conglomerados financeiros respondendo por aproximadamente $86 \%$ do ativo total do setor. O resto distribui-se entre 1570 instituições. Essa concentração também está refletida na indústria de gestão de recursos de previdência complementar, onde, em dezembro de 2014, os cinco maiores gestores detinham aproximadamente $90 \%$ dos recursos do setor. 
Apesar do bom resultado na parte ativa obtido pelos fundos Master, devido às altas taxas incidentes nos demais fundos (taxas de administração e taxa de performance) isso não se traduz em bons rendimentos para os investidores, evidenciado pelos resultados insatisfatórios da categoria como um todo. Fica evidente o lado perverso da enorme concentração do setor. Os gestores absorvem, através das taxas cobradas, todo o excesso de retorno gerado nas carteiras. Em relação ao comparativo entre gestores nacionais e estrangeiros, não se pode afirmar que existe diferença significativa entre eles. 


\section{2 \\ Sistema de Previdência Complementar}

O sistema público de assistência, incluindo a previdência é um sistema de financiamento de repartição (pay as you go), isto é, os benefícios pagos são financiados pelas contribuições cobradas da população ativa, sem capitalização de reservas. Há, assim, um pacto entre gerações, em que a população ativa financia a aposentadoria da população inativa.

A previdência privada não pretende substituir a previdência social, cujo papel na redistribuição de rendas é de fundamental importância para se alcançar os valores consagrados na Constituição, como a solidariedade, o bem-estar, a justiça social; mas auxiliá-la no que a previdência social não for capaz de suportar.

O sistema de previdência privada complementar pode ser de dois tipos fechados ou abertos. As entidades fechadas de previdência complementar (EFPC), também conhecidas como fundo de pensão, são instituições sem fins lucrativos, com planos de previdência coletivos, organizados pelas empresas, denominadas patrocinadoras, com o objetivo de garantir o pagamento de benefícios a seus participantes. São fiscalizadas pela Superintendência Nacional de Previdência Complementar (Previc), segundo as diretrizes do Conselho Nacional de Previdência Complementar (CNPC). São mais antigos e possuem parte relevante dos recursos.

As entidades abertas de previdência complementar (EAPC) são entidades constituídas unicamente sob a forma de sociedades anônimas e têm por objetivo instituir e operar planos de benefícios de caráter previdenciário concedidos em forma de renda continuada ou pagamento único, acessíveis a quaisquer pessoas físicas. As funções do órgão regulador e do órgão fiscalizador são exercidas pelo Ministério da Fazenda, por intermédio do Conselho Nacional de Seguros Privados (CNSP) e da Superintendência de Seguros Privados (SUSEP).

Os planos de previdência privada complementar podem ser divididos fundamentalmente de acordo com o tipo de cobertura. A cobertura por sobrevivência poderá ser estruturada nas modalidades de Contribuição Variável e Definida em que o valor do capital segurado, pagável de uma única vez ou sob a 
forma de renda é calculado com base no saldo acumulado da respectiva provisão matemática de benefícios a conceder e no fator de cálculo; ou Benefício Definido em que o capital segurado, pagável de uma única vez ou sob a forma de renda, é estabelecido previamente na proposta.

Apesar da maioria dos recursos das EFPC ainda estar em planos de Benefício Definido, vale ressaltar o grande crescimento dos planos com Contribuição Variável e Definida nos últimos anos. A tabela 1 apresenta o volume do ativo total por modalidade de plano nos dois primeiros trimestres de 2014. É possível observar que há concentração de $72 \%$ no segmento Benefício Definido, sendo $10 \%$ e $18 \%$ correspondentes aos segmentos de Contribuição Definida e Variável. Em termos de crescimento percentual em relação ao período anterior, verifica-se um incremento de respectivamente $4 \%$ e $5 \%$ nesses segmentos, se comparado com o crescimento de $2 \%$ do Benefício Definido.

\begin{tabular}{|lcc|}
\hline Modalidade de Plano & $1^{2}$ Tri/2014 & $2^{\mathfrak{Q}}$ Tri/2014 \\
\hline Benefício Definido & 496.046 .604 & 506.398 .583 \\
\hline Contribuição Definida & 64.278 .957 & 66.878 .828 \\
\hline Contribuição Variável & 121.973 .387 & 127.971 .601 \\
\hline Total & 682.298 .949 & 701.249 .012 \\
\hline
\end{tabular}

Tabela 1 - Ativo Total dos planos EFPC - Segundo modalidade. Fonte: Previc.

Em relação à concentração por modalidade de plano, a figura 1 mostra a evolução, em percentual, do ativo total dos planos pela totalidade das entidades fechadas de previdência complementar. Observa-se que, desde 1994, vem ocorrendo crescimento consistente no percentual da modalidade Contribuição Definida, em contrapartida ao decréscimo do Benefício Definido e estabilidade da concentração da Contribuição Variável. 


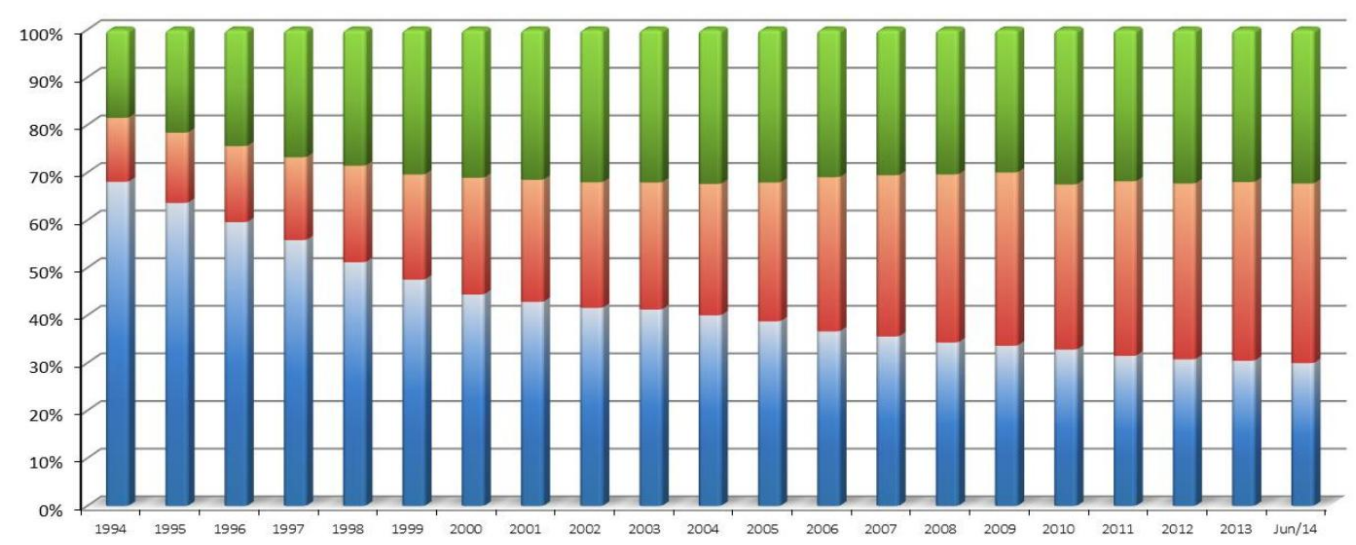

Menefício Definido $\square$ Contribuição Definida \Contribuição Variável

Figura 1 - Modalidade dos planos de EFPC. Evolução percentual. Fonte: Previc.

Em se tratando de estudo de desempenho de entidades de previdência complementar há que se enfatizar a diferença entre planos de Benefício Definido e os outros. Nos planos de Benefício Definido, existe a regulamentação do passivo atuarial com suas consequentes metas atuariais a serem cumpridas pelos gestores dos fundos de forma a conseguir atingir a necessidade de desembolso prevista nos planos. Caso a meta não seja atingida, são reajustadas as contribuições de forma a adequar a necessidade atuarial. No caso de planos de Contribuição Variável e Definida, tais metas não existem. Portanto, torna-se fundamental levar em consideração o desempenho dos gestores na formação dessa poupança, principalmente em relação aos índices de mercado, ou benchmarks. Tendo em vista a possibilidade de investimento em diversos ativos financeiros com certo grau de liberdade é de se esperar que o gestor seja capaz de utilizar-se das mais modernas técnicas de alocação de recursos com vista à obtenção de maior retorno possível, compatível com o risco alocado.

Os dois principais planos de previdência complementar aberta são o Plano Gerador de Benefício Livre (PGBL) e o Vida Gerador de Benefício Livre (VGBL). Segundo a SUSEP a sua regra de funcionamento é a mesma. Tanto o PGBL quanto o VGBL são planos que, durante o período de diferimento a remuneração da provisão matemática de benefícios a conceder é baseada na rentabilidade da(s) carteira(s) de investimentos de fundos de investimento especialmente constituídos - FIE(s), no(s) qual(is) esteja(m) aplicada(s) a totalidade dos respectivos recursos, sem garantia de remuneração mínima e de atualização de valores e sempre 
estruturados na modalidade de contribuição variável. Entretanto, têm natureza diversa, o que acaba por refletir na sua principal diferença: a tributação.

Os VGBL funcionam como um seguro de vida e, portanto, não entram no inventário, deixando de ser taxados pelo ITCMD. Adicionalmente, quando interpretados como seguro, também são impenhoráveis, não podendo sofrer bloqueio judicial em ações trabalhistas, cíveis, etc.; Quanto ao Imposto de Renda, o mesmo incide apenas sobre a rentabilidade acumulada até o momento do resgate do benefício.

Já o PGBL é mais claramente um plano de previdência, onde a principal característica é a possibilidade de dedução das contribuições no cálculo do imposto de renda, até um limite de $12 \%$ da renda total tributável. Quando dos resgates, a tributação incidirá sobre o principal e os rendimentos. Pode ser regressiva - inicia com alíquota de $35 \%$ e atingindo $10 \%$ no final de 10 anos - ou progressiva, que dependendo da faixa tributária do contribuinte participante, pode chegar ao máximo de $27,5 \%$.

Apesar das semelhanças, a modalidade que mais vem crescendo no Brasil é a de planos do tipo VGBL. Segundo a FENAPREVI, no ano de 2014 até outubro, cerca de $85 \%$ da receita decorrente dos planos contratados era proveniente do tipo VGBL (figura 2).

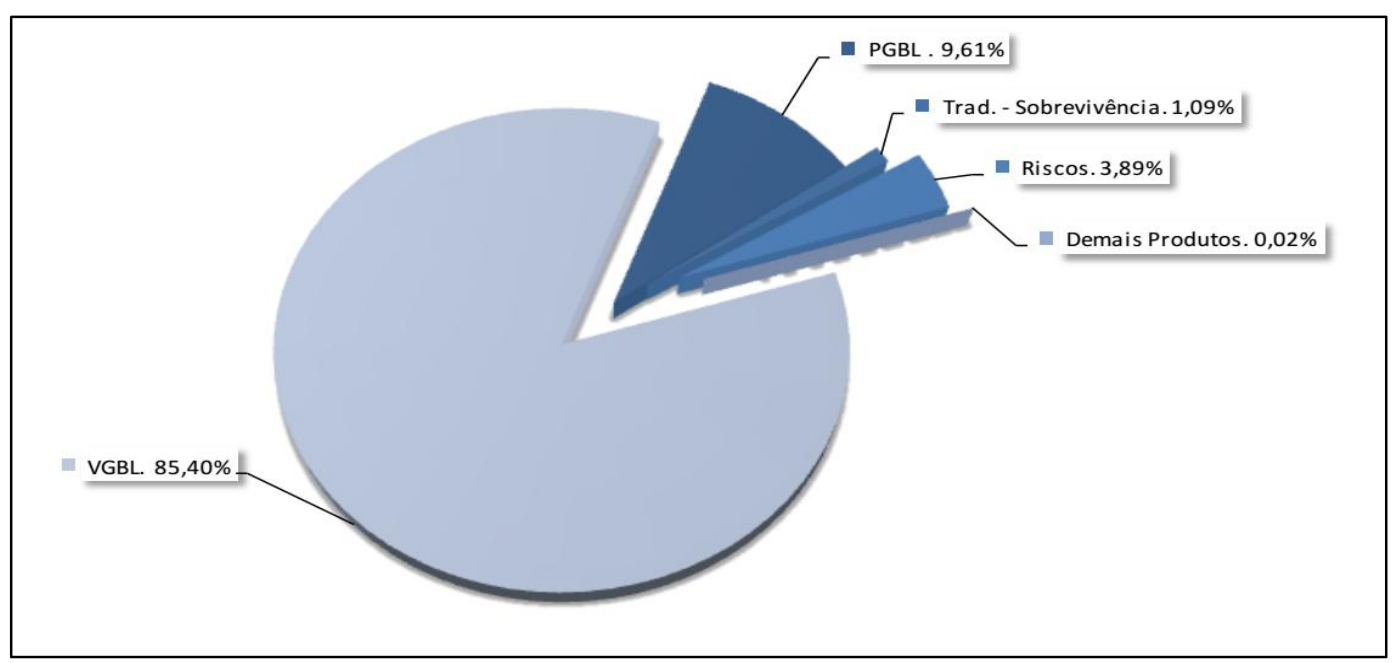

Figura 2 - Distribuição da receita por produto.

Fonte: Fenaprevi.

Esse forte crescimento já ocorre há alguns anos e tem resultado em uma maior participação dos planos do tipo VGBL no total de recursos administrados no setor. 
No último dado disponível, de outubro de 2014, o volume de planos VGBL já acumulava acima de $67 \%$ do total dos recursos destinados à previdência privada aberta complementar conforme figura 3.

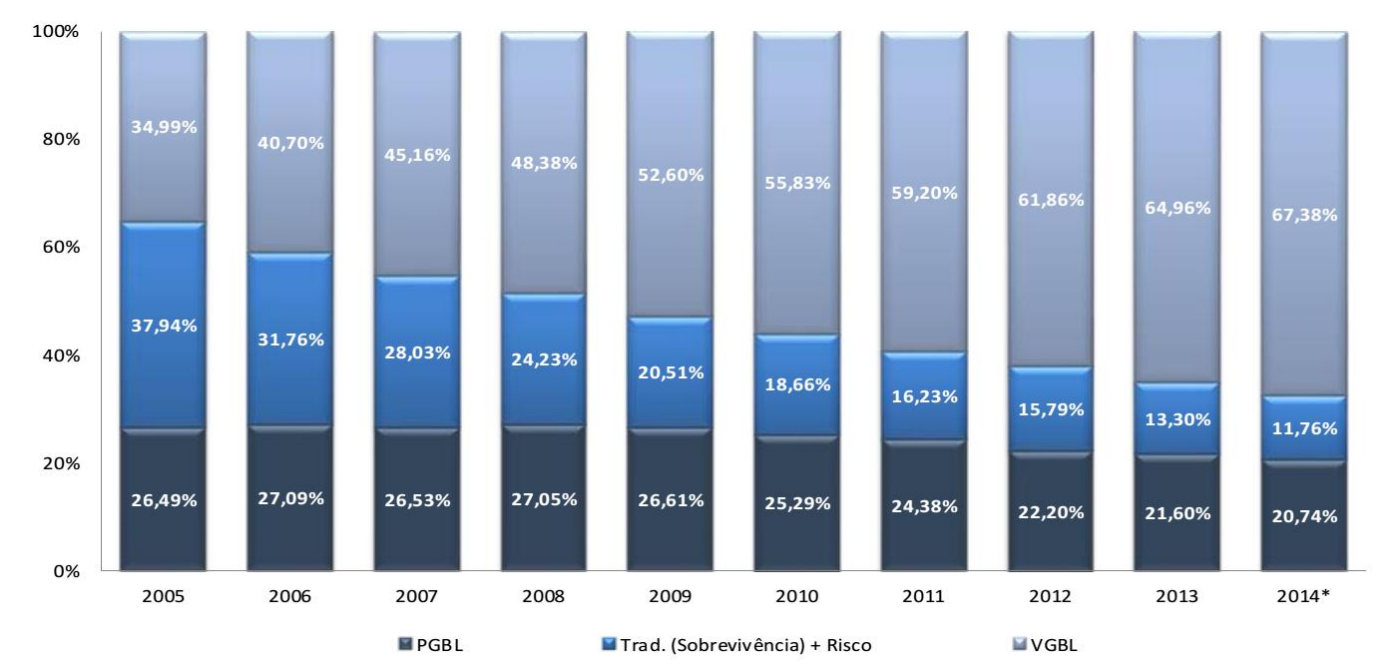

Figura 3 - Evolução da carteira de investimento por produto. Fonte: Fenaprevi.

A SUSEP através da circular 338/07 consolida diversas regras e critérios para as EAPC. Ela define que os fundos de investimento especialmente constituídos (ou fundos de investimento em quotas de fundos de investimento especialmente constituídos), são aqueles cujos únicos quotistas sejam, direta ou indiretamente, sociedades seguradoras e entidades abertas de previdência complementar ou, no caso de fundo com patrimônio segregado, segurados e participantes de planos VGBL - Vida Gerador de Benefício Livre ou PGBL - Plano Gerador de Benefício Livre.

Os planos do tipo PGBL ou VGBL deverão aplicar a totalidade dos recursos da provisão matemática de benefícios a conceder em quotas de FIEs. Poderão ser utilizados os mesmos FIEs para acolher recursos de diversos planos. Fica vedado às EAPC aplicar os recursos em quotas de FIEs cujo regulamento preveja cláusula de remuneração com base em desempenho ou performance.

Ela também assegura aos participantes o direito à portabilidade, inclusive para plano de benefício de entidade fechada, e ao resgate de recursos das reservas técnicas, provisões e fundos, total ou parcialmente. Além disso, afirma que a portabilidade não caracteriza resgate, sendo vedado, no caso de portabilidade que 
os recursos financeiros transitem pelos participantes, sob qualquer forma e que haja transferência de recursos entre participantes.

Em todos os tipos de plano VGBL ou PGBL, poderá ser prevista contratualmente a reversão de resultados financeiros durante o período de pagamento do capital segurado sob a forma de renda. Poderá ser cobrado carregamento para fazer face às despesas administrativas e de comercialização, ficando vedada a cobrança de inscrição e quaisquer outros encargos ou comissões incidentes sobre o valor dos prêmios, inclusive a título de intermediação. $\mathrm{O}$ valor do carregamento não poderá superar $10 \%$ (dez por cento) do prêmio efetuado para a cobertura estruturada na modalidade de contribuição variável e 30\% (trinta por cento) para a de benefício definido. 


\section{Revisão de Literatura}

\section{1}

Literatura sobre Análise de Desempenho de Fundos de Previdência e Fundos de Investimentos

\subsection{1 \\ Fundos de Previdência}

Segundo Beltrão et al. (2004), a previdência privada cresce em importância relativa na economia nacional, acompanhada de relevante evolução em sua legislação. Apesar da indústria de fundos abertos de previdência privada complementar no Brasil ser relativamente recente, estudos de desempenho dessa categoria de fundos vem crescendo. Lima (2006) avaliou uma amostra de fundos tipo PGBLs, com patrimônio líquido superiores a R $\$ 100$ milhões para o período de 2003 a 2004. O estudo de desempenho, por meio do índice de Sharpe, não encontrou excesso de retorno dos fundos em comparação à taxa referencial do CDI. Adicionalmente, Cardoso (2006) constatou que estatisticamente não é possível afirmar que a performance dos fundos de previdência complementar se repete no futuro, através de análise de persistência de performance utilizando os Índice de Sharpe, Treynor e Alfa de Jensen para o período entre 2001 e 2004. Já Bertucci, Souza e Félix (2006) concluíram que a alocação estratégica dos ativos no Brasil constitui-se em exercício de manutenção de aderência à meta atuarial do que propriamente em perseguição de rentabilidade.

Os estudos se intensificaram em 2010, quando Castro (2010) comparou fundos de previdência de renda fixa com os fundos de investimento de renda fixa tradicionais. Tomando como amostra fundos geridos por três bancos de varejo e dois bancos de nicho, constatou que os bancos estudados tinham gestão semelhante, voltada para o curto prazo, considerando o período de análise os retornos dos anos de 2005 a 2010. Já Yang et al. (2010) compararam o desempenho dos fundos de previdência e de investimento da categoria Referenciados DI e Renda Fixa, por 
meio do indicador Alfa de Jensen. Os resultados mostraram que na categoria Referenciados DI os fundos de previdência obtiveram melhor desempenho que os fundos de investimento, se comparado a categoria Renda Fixa onde os resultados foram opostos. Soma-se aos estudos citados, a análise do impacto do risco de longevidade em planos de previdência complementar de Silva (2010) que demonstra que não dar importância ao aumento da expectativa de vida na constituição das provisões técnicas pode expor as entidades de previdência a riscos pouco suportáveis no longo prazo.

E, mais recentemente, Amaral (2013) obteve como resultado, sobre o desempenho dos Fundos de Previdência Renda Fixa que, em todo o período estudado (2005 a 2011), que os retornos dos fundos ficaram abaixo da taxa livre de risco, representada na pesquisa por $96 \%$ da taxa Selic. Não encontrou excesso de retorno na comparação entre os retornos dos fundos e a taxa Selic. Consequentemente, quando calculado o IS e o $\mathrm{M}^{2}$, o desempenho apresentou-se negativo para a grande maioria dos fundos. Uma das explicações possíveis segundo Amaral seria o impacto da taxa de administração. Sua pesquisa obteve como resultado que as taxas de administração dos fundos de previdência de renda fixa foram maiores que as dos fundos de renda fixa não-previdenciários.

\subsection{2}

\section{Fundos de Investimentos}

No Brasil, os estudos de análise de desempenho de fundos começam com Vital (1973), que num período de 4 anos, entre 1968 e 1972 estudou a performance dos dez maiores fundos de investimento da época, utilizando os índices de Treynor e de Sharpe. Ele chegou à conclusão de que os fundos apresentaram resultados inferiores em todo o período estudado. A recomendação dele foi incentivar a maior concentração da indústria de fundos de modo a diminuir custos e melhorar o desempenho.

Ao estudo de Vital, seguiram os de Sanvicente e França (1989) e Savoia (1990) onde os fundos apresentaram resultados desanimadores, com retornos inferiores à taxa livre de risco.

Em artigo apresentado por Securato, Chára e Senger (1998) é feito um estudo para os fundos de renda fixa do mercado brasileiro, no período após crise da Ásia 
(03/11/1997 a 30/06/1998). A análise foi baseada em Sharpe (1992), considerando uma amostra de 153 fundos de diferentes modalidades de prazo (curto prazo, $30 \mathrm{e}$ 60 dias) e classificações diversas (Renda Fixa, DI, Derivativos Agressivo, Moderado e Conservador). Utilizando a técnica de regressão múltipla foi possível indicar a composição da carteira dos fundos de acordo com as principais classes de ativos, obtendo assim, a composição de um título sintético que possui o mesmo retorno médio e risco dos fundos de investimento em análise.

De acordo com Securato et al. (1999), a estabilização da economia brasileira obtida após o plano real elevou a demanda por fundos de investimentos e os investidores passaram a identificar os ganhos reais proporcionados pelos fundos com mais facilidade. Dentro de um cenário de taxas reais inferiores e maior competição entre os fundos, os investidores passaram a usar com mais frequência os indicadores de performance de fundos. Os autores elaboraram um ranking de fundos de renda fixa, de aproximadamente 800 fundos, utilizando os indicadores de retorno médio, risco, volatilidade, Sharpe, Modigliani, Sortino, Beta, R2 e percentual do parâmetro.

As decisões de realocação, assim como de novos investimentos, são muitas vezes tomadas em função desses indicadores. Conforme destaca Varga (2006), o índice de Sharpe é utilizado para a tomada de decisão de investidores e os recursos são alocados em função do seu resultado.

Ainda no mesmo ano, Lima (2006) obteve como conclusão que, na média, os fundos não conseguiram, no período estudado (2003 e 2004), superar o benchmark, ou seja, que não há excesso de retorno na comparação entre os retornos dos fundos e o CDI. Vilella e Leal (2008) introduziram o estudo do IRF-M (Índice de Renda Fixa de Mercado baseado em títulos prefixados) na análise de desempenho dos fundos de investimento de Renda Fixa, como benchmark alternativo e complementar ao CDI. Foram avaliados 212 fundos e os resultados indicam que o impacto econômico do IRF-M é baixo quando comparado ao CDI.

Quanto ao grau de atratividade dos fundos de investimentos de renda fixa, Vilella e Leal (2008) discutiram as possibilidades de produtos dos três maiores bancos de varejo em atividade no Brasil (Itaú - 11 fundos, Banco do Brasil- 19 fundos e Bradesco - 13 fundos). Foi aplicada a metodologia DEA de Análise Envoltória de Dados, considerando as características da estrutura de oferta, das rentabilidades e grupos de risco dos referidos fundos. O objetivo foi verificar a 
condição competitiva de cada fundo em termos de atratividade, pela análise de custo versus benefício. Não se percebeu, contudo, que as diferenças dos fundos pudessem ser atribuídas às instituições ou aos tipos e prazos dos fundos. Ou seja, o desempenho do fundo, em termos de estrutura de oferta versus rentabilidade, está relacionado às suas características individuais, não se encontrando vantagens atribuídas aos grupos (instituição, tipo ou prazo)

Já na parte dos fundos de ações no Brasil, Oda (2007) encontrou como resultado que a maior parte dos administradores não conseguiu retornos acima do Ibovespa e não demonstraram habilidade de timing e seletividade.

Drago e Brito (2012) em uma pesquisa de 85 fundos de investimentos multimercados, com uso do modelo APT, obtiveram como resultado que em $85 \%$ dos casos não foi encontrado alfa positivo com significância estatística.

No mercado americano de fundos de investimentos, onde a indústria desse segmento possui um nível de maturidade avançado frente à indústria no Brasil, Blake, Elton e Gruber (1993) estudaram os fundos de renda fixa (bond funds) tomando como base duas amostras: a primeira considerando 46 fundos, sendo 10 não sobreviventes, numa janela de 10 anos (1979-1988) e a segunda amostra incluindo todos os fundos (cerca de 200 fundos) até 1991. O objetivo foi avaliar a performance das amostras utilizando o modelo de fatores múltiplos. Descobriram que, em média, as performances dos fundos de renda fixa tiveram comportamento abaixo dos indicadores relevantes e não encontraram evidências de previsibilidade utilizando o desempenho passado para prever o desempenho futuro.

Um debate importante na literatura americana é exatamente sobre a persistência de desempenho dos fundos: se os retornos passados ajudam a prever retornos futuros. Elton, Gruber e Blake (1996) encontraram evidências de que o desempenho ajustado por risco ajuda a prever retornos ajustados no longo prazo, consistente com o fato de que gestores diferentes possuem níveis de habilidade diferentes.

Em 1997, Detzler (1997), desenvolveu estudo sobre o comportamento do risco e retorno entre 1988 e 1995 de 19 fundos de gestão ativa - global and international bond funds selecionados do ranking do Morningstar e da Wiesenbergercom. Detzler concluiu que os fundos não demonstraram desempenho superior, líquido de despesas, contra os índices de referência de mercado, sugerindo 
que as taxas de administração podem ter superado os benefícios da diversificação durante o período de amostragem.

Outro ponto de discussão na avaliação de desempenho da indústria de fundos americana é acerca da influência do tamanho do patrimônio líquido dos fundos na rentabilidade. Chen et al. (2004) argumentam que um grande fundo pode obter ganho de escala reduzindo despesas administrativas e tendo mais recursos para investir em pesquisa. Para Ciccotello e Grant (1996), o poder de barganha e a diluição de custos são vantagens dos fundos com grandes patrimônios. Porém, o aumento do patrimônio líquido traz desafios à gestão, pois dificulta a gestão dos ativos uma vez que encontrar oportunidades de investimentos pode ultrapassar a sua capacidade de se implementá-las.

Por fim, nas discussões sobre fundos, um dos pontos relevantes são os fatores institucionais, principalmente em mercados emergentes, em que os riscos políticos, os altos impostos cobrados e as poucas práticas de boa governança corporativa são comuns. Com essas afirmações, Khorana, Servaes e Tufano (2005), por meio de vários indicadores, como a razão entre o tamanho da indústria de fundos e o PIB do país, avaliam os fatores institucionais em diversos países do mundo. Concluem, portanto, que, em países onde existem boas regras de mercado, leis atuais, bom nível de educação, disseminação da internet, maior circulação de jornais e menores taxas de transação, o mercado de fundos de investimento tende a ser maior e mais eficiente.

\section{2}

\section{Processo de Investimento}

Todas as escolhas feitas por investidores envolvem certo grau de incerteza com relação às suas consequências e certamente, a noção de risco como sinônimo de grau de incerteza em relação a eventos futuros não é recente na história da humanidade. No entanto, somente a partir do desenvolvimento do cálculo de Probabilidades e da Estatística criaram-se condições para que o risco pudesse ser tratado de forma quantitativa. A Moderna Teoria de Finanças, por sua vez, aceita de forma ampla a variância (ou o desvio-padrão) dos possíveis resultados como uma medida do risco. A variância como medida de risco, proposta inicialmente por Markowitz (1952), permitiu que se atribuísse um número a um conceito 
predominantemente qualitativo, tendo papel fundamental nos desenvolvimentos teóricos que se seguiram.

As decisões econômicas são tomadas por indivíduos, sendo, por consequência, condicionadas às suas atitudes em relação ao risco. Existe, entretanto, uma relação inversa entre risco e retorno, impossibilitando a maximização simultânea das duas variáveis. Esta relação é consequência dos investidores serem avessos ao risco e demandarem um retorno esperado maior por um risco maior. Determinado nível de rentabilidade desejado decorre, inevitavelmente, de um risco a ser suportado. Esta é, portanto, a primeira decisão do investidor: a definição das variáveis de risco e retorno aceitáveis.

O instrumento mais importante para lidar com o risco, sob a ótica do investidor, é a diversificação. Como consequência, o desvio-padrão dos resultados esperados para o ativo não é a medida de risco utilizada pelo investidor. $\mathrm{O}$ fator a ser considerado pelo investidor é a contribuição do ativo individual para o risco da carteira. Em outras palavras, ao investidor interessa a covariância entre os valores esperados do ativo em questão e os valores esperados de sua carteira. Um ativo com um grande desvio-padrão poderia ser considerado de alto risco quando analisado individualmente. Porém, se este ativo apresentasse tendências de valorização e de desvalorização contrárias às da carteira, sua aquisição seria um ato de prudência.

O mais conhecido modelo de diversificação ótima de carteira, no qual utiliza a análise de média-variância é o proposto por Markowitz. Este modelo, entretanto, assume um horizonte de investimento de um único período. Porém, normalmente investidores novos, desejam um planejamento de vários períodos no longo prazo, aceitando assumir mais risco que os investidores de mais idade. Além disso, investidores conservadores tendem a manter uma concentração maior em títulos de renda fixa pré-fixada em relação a ações se comparados aos investidores mais agressivos.

A chave é reconhecer que portfólios ótimos para investidores a longo prazo não precisam ser os mesmos que os de investidores a curto prazo. Investidores a longo prazo, que valorizam a riqueza não para si próprios mas para o padrão de vida que ela pode suportar, podem julgar riscos de forma diferente de investidores de curto prazo. O salário é outra consideração importante para investidores de longo prazo. Pode-se considerar que trabalhadores possuem um ativo implícito - riqueza humana - cujos dividendos são iguais ao salário. Este ativo não é negociável, de 
modo que os investidores não podem vendê-lo, mas eles podem ajustar seus ativos financeiros levando em consideração suas riquezas humanas implícitas. Para a maioria dos investidores, a riqueza humana é suficientemente estável em valor, o que leva os investidores a assumirem mais riscos em outros ativos.

A nível teórico, estes pontos são aceitos há vários anos. Samuelson (1963, 1969), Mossin (1968), Merton (1969) e Fama (1970) descreveram as condições restritivas sob as quais investidores de longo prazo devem tomar as mesmas decisões que os de curto prazo. Modigliani e Sutch (1966) afirmaram que títulos de longo prazo são ativos seguros para investidores de longo prazo e Stiglitz (1970) e Rubinstein (1975) construíram modelos teóricos rígidos que validam e ilustram este ponto. Mayers (1972) e Fama e Schwert (1977) questionaram em como a riqueza humana influencia a escolha do portfólio. Merton $(1971,1973)$ fornece uma linha geral para entendimento das demandas do portfólio de investidores de longo prazo quando as oportunidades de investimento variam com o tempo.

Uma razão para o lento desenvolvimento deste campo foi a dificuldade de solucionar o modelo intertemporal de Merton. Soluções fechadas para o modelo foram disponibilizadas somente em uns poucos casos especiais, nos quais resultam que portfólios de longo prazo devem ser os mesmos que portfólios de curto prazo. Recentemente esta situação começou a mudar, como resultado do aumento do poder de processamento de dados e do avanço de métodos numéricos de forma que problemas de escolha realista de portfólio multi-período pudessem ser resolvidos numericamente. Adicionado a isso, novas soluções fechadas para o modelo de Merton foram descobertas e algumas soluções analíticas aproximadas foram desenvolvidas (CAMPBELL; VICEIRA, 2002).

Neste contexto, Campbell e Viceira (2002) abordam uma série de pontos relevantes como fundamentos a serem considerados no processo de investimento. O livro mostra que a alocação ótima para investidores de longo prazo não necessariamente será a mesma para os investidores de curto prazo. Os investidores de longo prazo são "míopes" quando decidem pela mesma alocação ótima que os de curto prazo. Eles consideram apenas um intervalo de tempo para a tomada de decisão.

Sabe-se, contudo, que as oportunidades de investimento não são constantes pois a taxa de juro real oscila ao longo do tempo. Logo, investidores de longo prazo devem priorizar ativos de longo prazo. Além disso, o valor esperado de excesso de 
retorno para ações e renda fixa variam ao longo do tempo, ocasionando, com isso, uma variação do portfólio ótimo.

Além disso, investidores devem ajustar seus portfólios de acordo com o ciclo de vida. Isto é, investidores mais jovens podem correr mais riscos que investidores de idade mais elevada. Investidores jovens tendem a optar por ativos com maior risco, como ações, e a medida que vão se aproximando da aposentadoria, buscam ativos de renda fixa. Há evidências também, que o investimento em ações pode sustentar um padrão de vida estável no longo prazo. Apesar de sua alta volatilidade no curto prazo e grande incerteza dos retornos médios no longo prazo, fazendo com que investidores conservadores optem por uma alternativa de menor risco, estes efeitos são diluídos ao longo do tempo. Normalmente, os choques de volatilidade tendem a ser transitórios no longo prazo e a previsibilidade do retorno de ações possui a característica de reversão à média.

Enfim, a grande questão crítica levantada em relação aos modelos tradicionais de escolha de portfólio é, portanto, que investidores podem tomar decisões mais acertadas caso levem em consideração uma combinação de variáveis consideradas relevantes para escolha do portfólio ótimo: preferências, restrições, expectativas, fluxo de renda, horizonte de tempo e até mesmo a previsão para aposentadoria.

\section{3}

\section{As Principais Medidas de Desempenho}

A análise de desempenho tem um papel fundamental na área de gestão de carteiras. São ferramentas fundamentais de auxílio aos investidores na comparação de investimentos e na avaliação dos valores adicionados pelos gestores. Além disso, a literatura de performance se depara com a importante tarefa de verificar se as taxas de performance (ou desempenho) cobradas por gestores remuneram suas supostas habilidades superiores de obter um excesso de retorno.

Ao longo dos últimos 50 anos foram publicados estudos variados e desenvolvidas diversas métricas de avaliação de desempenho. Segundo Caporin et al. (2014), podemos agrupar as medidas de performance em quatro grandes grupos ou famílias: medidas de desempenho relativo (por exemplo índice de Sharpe), medidas de desempenho absoluto (por exemplo alfa de Jensen), medidas baseadas 
em densidade (por exemplo Omega de Keating e Shadwick) e medidas baseadas em utilidade (por exemplo o MRAR do Morningstar).

\subsection{1}

Alfa

A medida de performance mais intuitiva e famosa é o Alfa. Na década de 30, Cowles (1933) iniciava o estudo do conceito com um artigo onde tentava medir a capacidade de adivinhação dos gestores da época. Ele buscava responder se tal habilidade tinha significância estatística, ou se era devida ao acaso.

Todavia, foram os trabalhos de Jensen $(1967,1972)$ e Sharpe (1966) que ajudaram a popularizar o conceito. De acordo com Jensen (1967) a habilidade de superar o mercado consiste na capacidade de antecipar os movimentos individuais dos ativos em relação a um portfólio de referência e à capacidade de prever o comportamento geral do mercado como um todo. A primeira habilidade está relacionada à capacidade de seleção dos ativos - security selection - e a segunda refere-se a capacidade de timing, ou seja, alterar o beta da carteira, ao longo do tempo, de acordo com a sua expectativa em relação ao mercado. Se o alfa é positivo o gestor gerou retorno acima do esperado pelo nível de risco da carteira, o que pode ser intuitivamente verificado através da sua fórmula:

$$
\alpha_{i}=R_{i}-R_{f}-\beta_{i}\left(R_{M}-R_{f}\right)
$$

Onde:

$\mathrm{R}_{\mathrm{i}}$ é o retorno médio do fundo $i$ no intervalo considerado

$\mathrm{R}_{\mathrm{f}}$ é a média da taxa de juros livre de risco no intervalo considerado

$\beta_{\mathrm{i}}$ é o beta do fundo do fundo $i$ no intervalo considerado

$\mathrm{R}_{\mathrm{M}}$ é o retorno médio do índice de mercado no intervalo considerado

Se o gestor tiver uma expectativa positiva em relação ao mercado, ele deve aumentar o seu beta, procurando absorver esse ganho no seu portfólio. E vice versa; caso espere um movimento negativo, deve diminuir ou até mesmo proteger completamente - hedge - a carteira. Se o gestor possuir capacidade de previsão superior ele será capaz de prover o seu cliente, ou investidor, de um excesso de 
retorno ou um retorno anormal sobre uma carteira de mercado estática. Diz-se então que o gestor gerou um alfa positivo.

\subsection{2}

\section{Índice de Sharpe}

O Índice de Sharpe ou Sharpe Ratio é a mais usada e comum medida de se determinar um excesso de retorno ajustado ao risco. Ela se baseia na hipótese que os retornos são normalmente distribuídos ou que o investidor possui uma função utilidade onde o que importa são a expectativa de retornos e a variância (ou desvio padrão). A simplicidade e a facilidade de cálculo favoreceram a sua difusão entre instituições e investidores. Quando proposta inicialmente (SHARPE, 1966) como um quociente $\mathrm{R} / \mathrm{V}$ ou reward-to-variability evidenciava a intenção do autor e a proximidade das teorias de carteiras desenvolvidas por Markowitz na década de 50 . Seria a recompensa fornecida ao investidor pelo maior risco incorrido. Com isso sua formulação original é apresentada da seguinte forma:

$$
\text { Índice de Sharpe }=\frac{R_{i}-R_{f}}{\sigma_{i}}
$$

Onde:

$\mathrm{R}_{\mathrm{i}}$ é o retorno médio do fundo $i$ no intervalo considerado

$\mathrm{R}_{\mathrm{f}}$ é a média da taxa de juros livre de risco no intervalo considerado

$\sigma_{\mathrm{i}}$ é o desvio padrão do retorno do fundo $i$ no intervalo considerado

Apesar de suas vantagens, o Índice de Sharpe apresenta também algumas fraquezas. Em primeiro lugar ele não serve para quantificar o valor adicionado (caso haja); serve apenas para ranquear os fundos. Além disso é muito sensível à escolha da taxa de juros livre de risco, tendo em vista que a sua interpretação quando resulta em um número negativo é um pouco complexa.

Outra fraqueza advém do uso do desvio padrão como medida de risco aliada à suposição de que os retornos possuem uma distribuição gaussiana. Para tratar essas questões diversos autores sugerem alguns ajustes metodológicos. Mahdavi (2004) sugere um Índice de Sharpe ajustado para avaliar ativos cuja a distribuição não seja normal. Lo (2002) demonstra que há correlação serial nos retornos para 
fundos hedge e sugere uma nova fórmula que inclua uma correção do viés. Outros como Hodges (1998) e Zakamouline e Koekebakker (2009) defendem ajustes decorrentes da presença de opções nos portfólios que alteram o formato das distribuições de retorno. Por último, mas não menos importante, há a questão da forma de cálculo consagrada. Nela são utilizadas as medidas de retorno e volatilidade históricos, ao invés de prospectivos, conforme preconizava o modelo de otimização de carteiras.

Sharpe (1994) retoma o tema e discute os aspectos práticos do cálculo. Assume que apesar de a teoria ser prospectiva, ou seja, sugerir usar valores ex-ante, o cálculo ex-post também pode dar alguma luz, desde que o investidor esteja ciente que implicitamente está assumindo que os valores históricos possuem algum grau de previsibilidade. Além disso, ele amplia o conceito para o uso em comparação a um benchmark e não só em relação ao ativo livre de risco. Com isso a fórmula ampliada passa a ser definida ex-post da seguinte forma. Seja $\mathrm{R}_{\mathrm{At}} \mathrm{o}$ retorno do fundo no período $t, \mathrm{R}_{\mathrm{Bt}} \mathrm{O}$ retorno do benchmark no período t e $\mathrm{D}_{\mathrm{t}} \mathrm{o}$ diferencial de retorno no período t:

$$
D_{t}=R_{A t}-R_{B t}
$$

Seja D-barra a média dos valores de $\mathrm{D}_{\mathrm{t}}$ no período histórico de $\mathrm{t}=1 \mathrm{a} \mathrm{T}$.

$$
\bar{D} \equiv \frac{1}{T} \sum_{t=1}^{T} D_{t}
$$

E $\sigma_{D}$ o desvio padrão sobre o período.

$$
\sigma_{D} \equiv \sqrt{\frac{\sum_{t=1}^{T}\left(D_{t}-\bar{D}\right)^{2}}{T-1}}
$$

Dessa forma o Índice de Sharpe histórico $\left(\mathrm{S}_{\mathrm{h}}\right)$ é dado por:

$$
S_{h} \equiv \frac{\bar{D}}{\sigma_{D}}
$$




\subsection{3}

\section{Índice de Treynor}

Um ano antes de Sharpe introduzir o seu índice, Treynor (1965) desenvolvia o seu, mas utilizava o risco sistemático do portfólio no denominador. Além das desvantagens do Índice de Sharpe, ao depender de um benchmark no denominador, o Índice de Treynor depende do beta, de difícil medição e que varia de acordo com a exposição ao mercado. O seu cálculo não é excessivamente complexo, tendo em vista que para um portfólio o seu beta é uma média ponderada dos betas individuais. O estimador do Índice de Treynor é:

$$
I T \equiv \frac{\overline{R_{l}}-\overline{R_{f}}}{\hat{\beta}_{i}}
$$

Onde:

$\mathrm{R}_{\mathrm{i}}$ é o retorno médio do fundo $i$ no intervalo considerado

$\mathrm{R}_{\mathrm{f}}$ é a média da taxa de juros livre de risco no intervalo considerado

$\beta_{\mathrm{i}}$ é o beta do fundo $i$ no intervalo considerado

Como variação temos o Índice Black-Treynor que considera o alfa como medida de excesso de retorno no numerador, ou seja:

$$
I B T \equiv \frac{\alpha_{i}}{\hat{\beta}_{i}}
$$

Onde:

$\alpha_{\mathrm{i}}$ é o alfa do fundo $i$ no intervalo considerado

\subsection{4 \\ Medida Ômega}

Se a função utilidade do investidor é quadrática, sua utilidade esperada é função apenas dos dois primeiros momentos da distribuição. Portanto média e variância são suficientes para resolver o problema de maximização mesmo quando os retornos não são normalmente distribuídos. Para os portfólios com grande quantidade de ativos com alguma opcionalidade embutida, o que altera significativamente a função de distribuição dos retornos, Keating e Shadwick 
(2002b) procuraram desenvolver uma medida que funcionasse de forma independente do formato da função dos retornos.

Chamaram de razão Ômega, ou medida Ômega a razão, em relação a um parâmetro definido de rentabilidade, das áreas de ganho e perda na função dos retornos. Com essa especificação puderam obter insights mais abrangentes em relação ao comportamento da função de distribuição de retornos. A maior razão Ômega indica que o ativo proporciona mais ganhos em relação às perdas para algum parâmetro definido de rentabilidade (r) e assim seria preferido por um investidor. 0 indicador pode ser estimado pela fórmula:

$$
\Omega(r)=\frac{\int_{r}^{\infty}(1-F(x)) d x}{\int_{-\infty}^{r} F(x) d x}
$$

Onde:

r é o parâmetro definido de rentabilidade que divide as áreas de ganho e perda $\mathrm{F}(\mathrm{x})$ é a função distribuição dos retornos do ativo no intervalo considerado

Como crítica à medida, destaca-se o fato de ser muito dependente da definição do parâmetro que separa a distribuição entre ganhos e perdas e também por ser muito mais influenciadas por outliers.

\subsection{5}

\section{Medida de Retorno Ajustado ao Risco do Morningstar}

O retorno ajustado ao risco do Morningstar (MRAR) - em inglês, Morningstar Risk Adjusted Return - é o mais famoso dos indicadores pertencentes à família de medidas de performance obtidas a partir de estudo das funções utilidades esperadas. A modelagem se apropria do processo decisório sob incerteza. No modelo o investidor toma a sua decisão de investimento baseado no valor esperado da função utilidade, de acordo com a sua preferência ou aversão ao risco. O objetivo da medida é ranquear os fundos de acordo com um valor esperado de retorno geométrico anualizado num certo horizonte de tempo. Com isso, vai classificar os fundos entre os que superaram o retorno e os que ficaram abaixo. A crítica ao modelo está associada aos valores utilizados para o coeficiente de aversão 
a risco, tendo em vista que tal medida é dinâmica, variando com as condições de mercados e com o perfil dos investidores.

A fórmula para $\gamma \neq 0$ é definida como:

$$
\operatorname{MRAR}(\gamma)=\left[\frac{1}{T} \sum_{t=1}^{T}\left(1+E R_{t}\right)^{-\gamma}\right]^{-\frac{12}{\gamma}}-1
$$

Sendo $\mathrm{ER}_{\mathrm{t}} \mathrm{o}$ excesso de retorno do fundo em relação ao ativo de risco no mês t e $\mathrm{T}$ o número de meses no período analisado. A modelagem do parâmetro $\gamma$ depende da aversão ao risco do investidor. Como regra geral, se $\gamma$ é menor que -1 o investidor é amante do risco. Se igual a zero ele é indiferente, desde que a média geométrica do retorno obtido seja a mesma, e se for igual a -1 ele também é indiferente desde que a média aritmética do retorno seja a mesma. Na prática, a maioria das modelagens assume que o investidor é avesso ao risco e portanto o parâmetro utilizado é acima de -1. Caporin et al. (2014) mostra que no sistema de ratings da Morningstar o parâmetro utilizado é igual a 2.

\subsection{6 \\ Tracking Error}

Hwang e Satchell (2001) e Larsen e Resnick (1998) descrevem que o tracking error pode ser definido de forma simples como a diferença entre o retorno do portfólio e o retorno do benchmark de referência. Assim, para qualquer tempo t, seria igual a

$$
y_{t}=r_{t}-b_{t}
$$

Onde:

$\mathrm{r}_{\mathrm{t}}$ representa o retorno do portfólio

$b_{t}$ representa o retorno do benchmark

Dessa forma, é facilmente calculado. As fontes mais comuns de desvios advém tanto das tentativas de superar ativamente o benchmark como da tentativa de replicá-lo de forma passiva. Vale ressaltar que uma gestão ativa ideal procura 
obter um tracking error positivo e com baixa volatilidade. Diversos autores, como Jorion (2003), Roll (1992), Poppe e Yadav ( 1994) e Rudolf, Volter e Zimmermann (1999) preferem definir a medida relevante de tracking error como o desvio padrão (ou variância) da diferença entre o retorno do portfólio e o retorno do benchmark. Assim, teríamos:

$$
T E=\sqrt{\frac{1}{n-1} \sum_{t}\left(y_{t}-\bar{y}\right)^{2}}
$$

Roll (1992) argumenta que como os retornos são cheios de ruídos, o foco deve ser em minimizar a volatilidade do tracking error. Entretanto alerta que utilizar-se apenas do critério de minimizar tal volatilidade pode levar a escolhas subótimas de portfólios, em desacordo com as regras de maximizar retorno minimizando risco preconizadas por Markowitz.

Por último, ainda pode-se diferenciar entre tracking error ex-ante e tracking error ex-post, sendo o mesmo obtido através de uso de modelo de previsão extraído de modelo de regressão entre o retorno do portfólio $\left(\mathrm{R}_{\mathrm{p}}\right)$ e o retorno do benchmark $\left(R_{\mathrm{b}}\right)$. O erro padrão da equação de regressão consistirá na estimativa do tracking error, conforme se segue.

$$
R p_{t}=\alpha_{i}+\beta_{i} R b_{t}+\varepsilon p_{t}
$$

\section{4}

\section{Análise de Estilo Baseada em Retornos}

A Análise de Estilo Baseada em Retornos é uma técnica estatística que procura identificar qual combinação de índices passivos melhor consegue replicar as posições ativas de um fundo de investimento, em um período desejado. Os índices passivos representam diferentes estilos de investimento ou gestão dentro de uma particular classe de ativos.

Sharpe (1992) define o modelo genérico da seguinte forma:

$$
\widetilde{R_{\iota}}=\left[b_{i 1} \widetilde{F_{1}}+b_{i 2} \widetilde{F_{2}}+\cdots+b_{i n} \widetilde{F_{n}}\right]+\tilde{e}_{i}
$$


Onde:

$\mathrm{R}_{\mathrm{i}}$ representa o retorno no ativo ou portfólio i;

$F_{i}$ representa o valor do fator $i$

$b_{i j}$ representa a sensibilidade do $R_{i}$ aos fatores $F_{i}$ ao $F_{n}$.

$\mathrm{e}_{\mathrm{i}}$ é o componente "não fator" do retorno $\mathrm{R}_{\mathrm{i}}$.

O pressuposto fundamental do modelo é que os componentes residuais $\left(\mathrm{e}_{\mathrm{i}}\right)$ não apresentam correlação entre si. Os fatores são as únicas fontes de correlação entre os retornos.

O objetivo é encontrar o "melhor" conjunto de exposição aos ativos $\left(b_{i j}\right)$ que somem 1, respeitem informações sobre a política de investimento do fundo, e minimizem a variância dos $\mathrm{e}_{\mathrm{i}}$.

Os valores e e são chamados de "tracking errors" e a sua variância de "tracking variance". Uma dificuldade na aplicação do modelo é o pressuposto implícito que os fundos mantêm pesos constantes ao longo de todo o período de análise. Alguns autores como Kim, Shukla e Tomas (2000), Swinkels e Van Der Sluis (2006) e Chan, Chen e Lakonishok (2002) encontraram mudanças de estilo ao longo do tempo. Apesar dessa dificuldade, a análise de estilo é largamente empregada como um meio de monitorar se o gestor está seguindo a política de investimento declarada. 


\section{4 \\ Dados e Metodologia}

O presente estudo foi realizado em fundos pertencentes à categoria de fundos de previdência renda fixa, segundo classificação da Anbima. Esses fundos investem em ativos de renda fixa, reais ou sintéticos, e não têm permissão para manter exposição com risco de moeda estrangeira ou renda variável.

Essa pesquisa visa responder as seguintes perguntas:

a) As carteiras dos fundos de investimento de previdência renda fixa conseguem obter indicadores de Sharpe positivo?

b) As carteiras dos fundos de investimento de previdência renda fixa são diversificadas?

c) Existe diferença entre os Índices de Sharpe de gestores nacionais e gestores estrangeiros?

d) As carteiras dos fundos Master conseguem obter Índices de Sharpe positivos?

Dado que analisamos fundos de previdência renda fixa, o uso de certos indicadores de desempenho que se utilizem da prerrogativa de investimento em ativos de renda variável não parece ser recomendado. De tal forma que orientamos a análise tal como recomendado por Blake, Elton e Gruber (1993). Os autores sugerem que seja estruturado um benchmark para que se proceda a análise. Para tal será usada a metodologia já consagrada e sugerida por Sharpe chamada de Análise de Estilo Baseada em Retornos de forma a se obter quais os ativos são relevantes na montagem desse indicador.

A amostra utilizada nesta pesquisa corresponde a 382 fundos de investimento de previdência renda fixa, que representam aproximadamente $99 \%$ do total de fundos de previdência de renda fixa em atividade, cujos investimentos, no valor de aproximadamente R $\$ 400$ bilhões, corresponde a 15\% do total dos investimentos de todos os fundos de investimento do Brasil, no valor total de R \$ 2,7 trilhões, em dezembro 2014. Trata-se de uma amostra não aleatória. 
O período amostral compreende os meses de janeiro de 2003 a dezembro de 2014 e os dados primários são compostos de cotas diárias e os secundários são taxas mensais. Objetivou-se, na escolha da amostra, capturar um percentual significativo dos investimentos dos fundos de investimento de previdência de renda fixa excluindo-se apenas um pequeno número de fundos. Ademais, dentre os fundos componentes da amostra estão os maiores fundos de investimento do país. Quanto ao período amostral, alcançou-se mais de 10 anos, ou até 144 observações, um período extenso o suficiente, mas recente, no qual se dispôs de dados completos e consistentes. Além do período completo, foram realizadas análises em dois subperíodos de 5 anos a fim de se confirmar os resultados e conferir maior robustez aos resultados. Os períodos escolhidos foram de janeiro de 2005 a dezembro de 2009 e de janeiro de 2010 a dezembro de 2014.

Segundo a KPMG, as estruturas de fundos Master/Feeder foram criadas nos EUA com o propósito de contornar questões tributárias. Criava-se o fundo Master em um local sem impostos e depois os fundos Feeders investiam nesses fundos. Em pouco tempo, diversas outras vantagens foram ficando evidentes. Dentre elas destacam-se: i) custos de transação reduzidos; ii) custos administrativos de gerenciamento e controle reduzido; iii) economias de escalas na gestão, com melhor poder de negociação e barganha; iv) melhor acesso a certos mercados ao cumprir diferentes regras de compliance e ser classificado como investidor qualificado e v) atender, simultaneamente, a diferentes nichos de investidores com taxas diferenciadas. Em contrapartida como desvantagem temos a dupla camada de certos custos e o aumento da complexidade dos fluxos financeiros.

Como parte representativa da indústria de fundos de previdência está organizada com o uso intensivo da estrutura de Master/Feeder, optou-se adicionalmente por extrair um subgrupo de fundos Master para compor uma subamostra de análise. Com isso a subamostra de fundos Master possui um total de 38 fundos e um volume financeiro de R \$ 360 bilhões em dezembro de 2014, representando cerca de $90 \%$ do volume do setor. Os gestores de fundos Master têm sob administração conjunta (Master + Feeders) um total de $98 \%$ do total dos recursos da amostra, o que comprova o uso disseminado da estrutura dentro do setor. Na tabela 2, abaixo, estão discriminados os principais gestores e como se distribuem os fundos por eles geridos. É interessante ressaltar que os cinco maiores gestores - Bradesco, Banco do Brasil, Itaú, Caixa e Santander são responsáveis por 
aproximadamente $92 \%$ do volume financeiro e, por pouco, mais de $50 \%$ dos fundos.

\begin{tabular}{|c|c|c|c|c|}
\hline Gestor & Master & Não Master & Total & $\%$ Recursos \\
\hline$A A A$ & & 1 & 1 & $*$ \\
\hline AGPrev & & 2 & 2 & $0,04 \%$ \\
\hline Alfa & 1 & 4 & 5 & $0,10 \%$ \\
\hline$A R X$ & & 1 & 1 & $*$ \\
\hline Banestes & & 1 & 1 & $*$ \\
\hline Banrisul & & 3 & 3 & $0,01 \%$ \\
\hline Banco do Brasil & 5 & 23 & 28 & $27,22 \%$ \\
\hline BNP Paribas & 1 & 4 & 5 & $0,06 \%$ \\
\hline Bradesco & 7 & 46 & 52 & $28,57 \%$ \\
\hline BTG Pactual & & 2 & 2 & $0,01 \%$ \\
\hline Caixa & 1 & 13 & 14 & $6,11 \%$ \\
\hline Citibank & & 6 & 6 & $0,09 \%$ \\
\hline CSHG & & 1 & 1 & $0,01 \%$ \\
\hline Fram Capital & & 1 & 1 & $0,01 \%$ \\
\hline$H S B C$ & 2 & 21 & 23 & $2,21 \%$ \\
\hline Icatu & 5 & 24 & 29 & $1,08 \%$ \\
\hline Itaú & 7 & 67 & 74 & $24,79 \%$ \\
\hline JP Morgan & 1 & 2 & 3 & $0,17 \%$ \\
\hline Mapfre & 1 & 5 & 6 & $0,30 \%$ \\
\hline Metlife & 1 & 2 & 3 & $0,07 \%$ \\
\hline Mongeral & & 5 & 5 & $0,04 \%$ \\
\hline Porto Seguro & 1 & 7 & 8 & $0,39 \%$ \\
\hline Safra & 1 & 8 & 9 & $0,89 \%$ \\
\hline Santander & 3 & 31 & 34 & $6,11 \%$ \\
\hline Schroder & & 1 & 1 & $0,06 \%$ \\
\hline Sicredi & 1 & 7 & 8 & $0,08 \%$ \\
\hline Sul América & & 15 & 15 & $0,33 \%$ \\
\hline Votorantim & & 5 & 5 & $0,08 \%$ \\
\hline Western Asset & & 3 & 3 & $0,02 \%$ \\
\hline$X P$ & & 1 & 1 & $*$ \\
\hline Zurich & & 2 & 2 & $0,01 \%$ \\
\hline Total & 38 & 314 & 352 & $98,88 \%$ \\
\hline
\end{tabular}

Tabela 2 - Distribuição de fundos por gestor.

Elaborado pelo autor.

O banco de dados dos fundos de investimentos foi obtido junto ao site da CVM. Os valores para o CDI Cetip foram obtidos junto a página da CETIP. As séries do IRF-M e IMA-B foram obtidos junto à página do BC. 
Os indicadores de desempenho relativos necessitam que seja feita uma escolha de índice ou índices de referência, os chamados benchmarks. No estudo de Blake, Elton e Gruber (1993) eles argumentam que para se obter uma medida de desempenho deve-se ter em mente que a seleção do índice de referência deve ser cuidadosa. A forma mais simples de selecionar é comparar a um portfólio passivo composto de um ou mais índices. Uma forma um pouco mais sofisticada seria comparar à uma carteira composta de índices que fosse do mesmo risco do fundo a ser analisado.

No Brasil existem poucos índices com significância econômica relativa ao mercado de renda fixa. Com regularidade e publicidade destacam-se os índices de mercado da Anbima (IMA). São uma família de índices que representam a evolução, a preços de mercado, da carteira de títulos públicos da dívida mobiliária federal. O IMA é subdividido em quatro subíndices, de acordo com os indexadores dos títulos que compõem o portfólio - pré-fixados, indexados ao IPCA, indexados ao IGP-M e os pós fixados à taxa SELIC. Assim temos os seguintes subíndices:

- IMA-B: Composto de títulos indexados ao IPCA (NTN-B)

- IMA-C: Composto de títulos indexados ao IGP-M (NTN-C).

- IMA-S: Composto de títulos indexados ao SELIC (LFT).

- IRF-M: Composto de títulos pré-fixados (LTN e NTN-F).

Vilella e Leal (2008) estudaram modelos de um fator e dois fatores (IRF-M e CDI) e concluíram que o CDI explica grande parte dos retornos e o IRF-M agrega informações apenas de forma marginal. Desde 2005 o governo vem conseguindo ampliar o perfil da dívida, tendo alcançado em dezembro de 2014 cerca de $41 \%$ da dívida como pré-fixada conforme mostra a figura 4. 


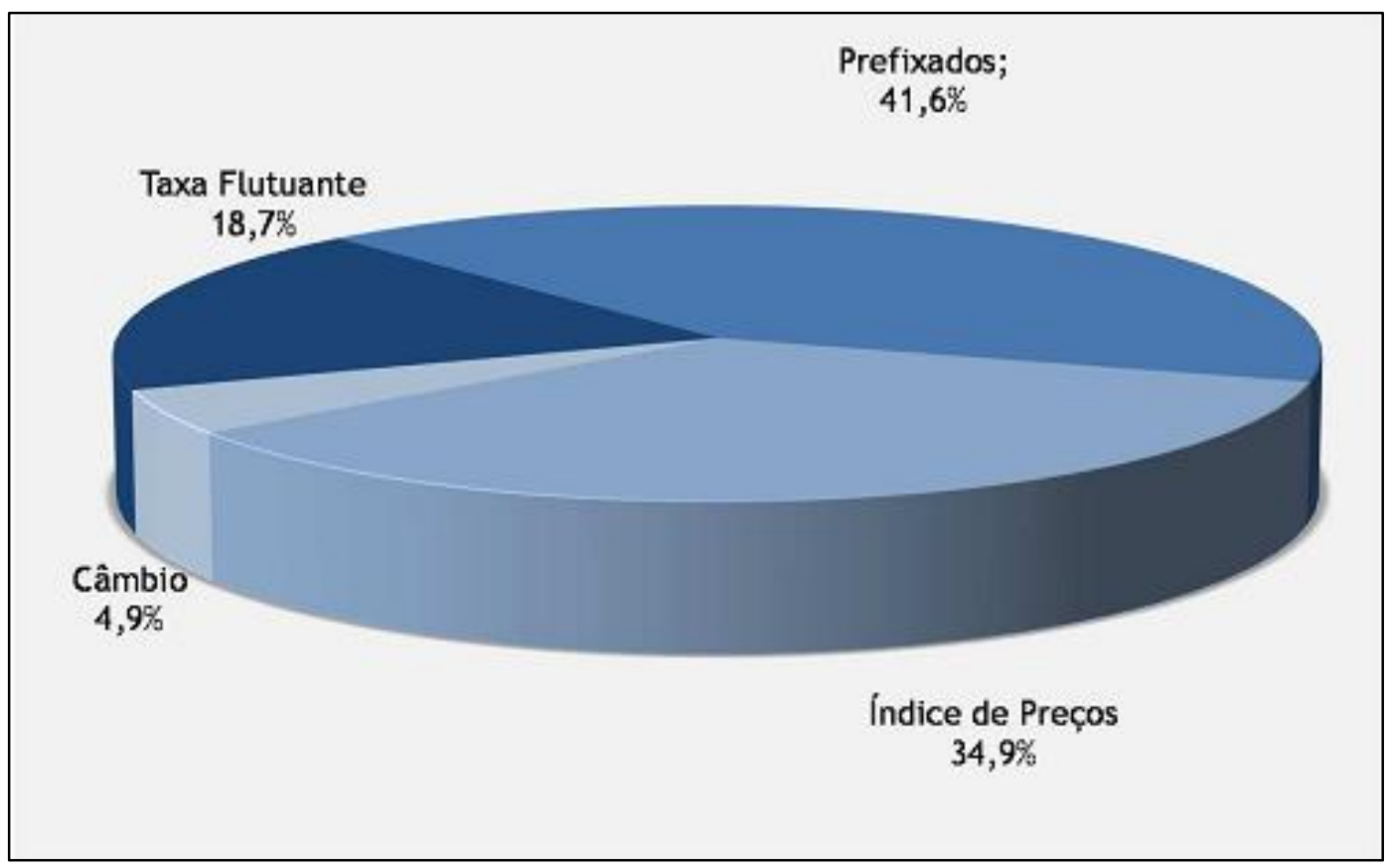

Figura 4 - Composição da dívida pública federal por indexador - Dez/2014. Fonte: Secretaria do Tesouro Nacional - STN.

Entretanto o prazo médio da dívida prefixada permanece ainda muito baixo: 1,93 anos em dezembro de 2014. Por conta disso a SELIC (ou sua proxy, o CDI) permanece como o indicador relevante. Na dívida privada o panorama é ainda mais desanimador. Segundo o boletim mensal de dezembro de 2014 divulgado pela Anbima, 90\% do estoque de títulos privados era indexado a CDI (figura 5).

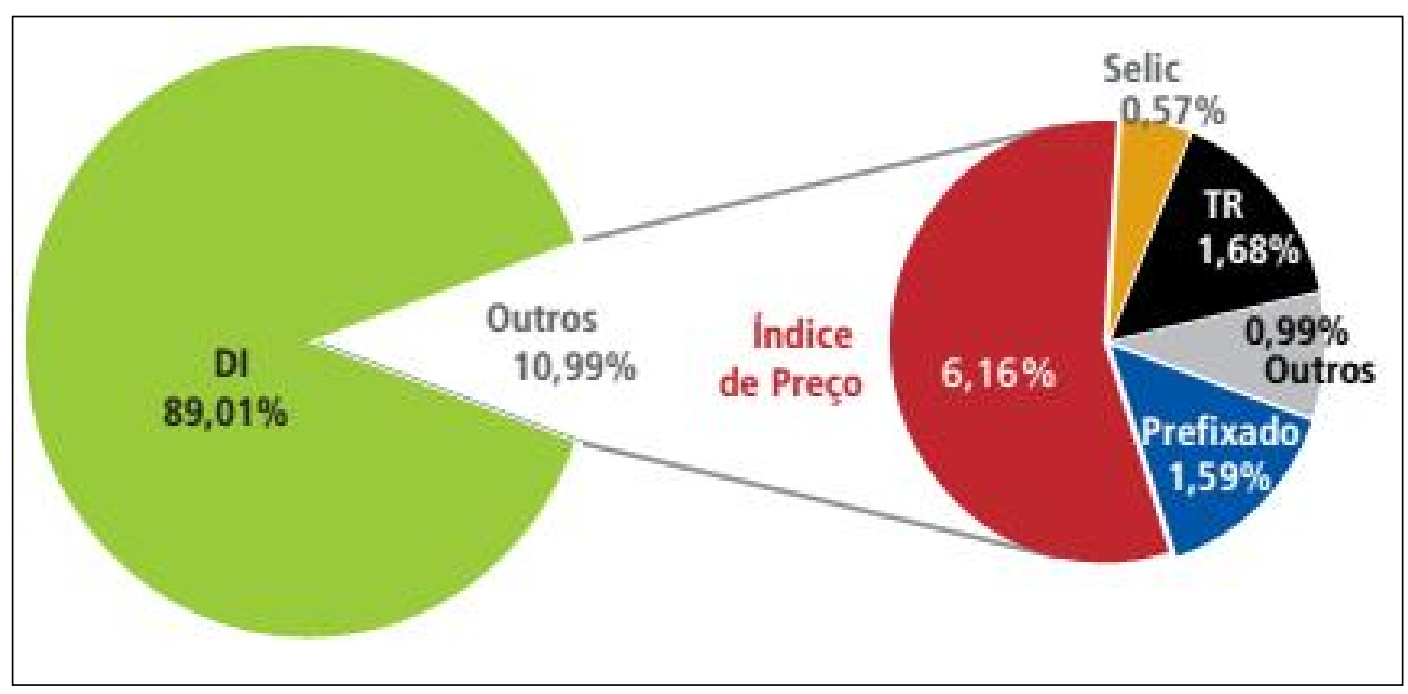

Figura 5 - Estoque de títulos privados por indexador. Fonte: Anbima e CETIP. 
Para definir qual índice usar, e tendo em vista as limitações da amostra, qual seja, de não poder investir em ativos indexados a renda variável ou a moedas, optouse por utilizar a Análise de Estilo Baseada em Retornos (SHARPE, 1992) para os indicadores IRF-M, CDI e IMA-B. Foram excluídos o IMA-S por ser uma proxy do CDI, e este ser mais amplamente utilizado pelo mercado, e o IMA-C por conter uma parcela muito pequena de ativos negociados.

$\mathrm{Na}$ preparação dos dados procurou se averiguar se podemos assumir que estamos trabalhando com uma amostra com distribuição normal. Para isso, consideraremos o uso dos testes de Kolmogorov-Smirnov com correção de significância de Lilliefors e do teste de Shapiro-Wilk, no caso de amostras pequenas (Razali e Wah, 2011), ambos obtidos através do uso do pacote estatístico SPSS versão 22 .

Além disso, também com o auxílio do pacote estatístico, utilizou-se a técnica de regressão simples e regressão múltipla, tendo a média dos retornos dos fundos como variável dependente e o retorno mensal dos índices IRF-M, IMA-B e CDI como variáveis independentes. O objetivo foi mensurar a capacidade dos índices de prever o retorno do fundo. Para tal foram realizados 2 testes de regressão. $\mathrm{O}$ primeiro, apenas com o CDI como variável independente. O segundo, incluíndo os três índices (IRF-M, IMA-B e CDI). E por último, também foram extraídas as estatísticas descritivas como o retorno médio, mediana e desvio padrão da amostra.

Como limitação do estudo, fica evidente que ele depende da classificação correta dos FIE por conta da área técnica da Anbima. Tanto em termos de tipos de ativos quanto abrangência da população de fundos. Além disso, a quase totalidade dos fundos não possui séries de retornos normais, o que enfraquece o resultado mas não inviabiliza o uso dos indicadores de performance. Na verdade, era pouco provável se obter uma distribuição normal em séries de retorno. Keating e Shadwick (2002a) relatam que é um fato estilizado e largamente aceito que a distribuição de retornos dos investimentos não é normalmente distribuída. Por outro lado, as ferramentas largamente utilizadas na avaliação de performance de fundos de investimento, em grande medida estão baseadas em que a média e a variância são medidas suficientes para descrever a distribuição de retornos. Por último, a análise se restringe à avaliação dos fundos de previdência renda fixa e não abrange os planos de previdência. Além das taxas de administração e performance cobradas 
sobre os fundos, os planos podem cobrar taxa de carregamento, o que afeta negativamente o resultado final dos investimentos.

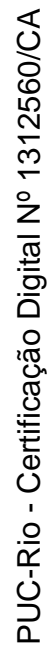




\section{5}

\section{Resultados}

O retorno médio dos fundos de investimento foi de $0,78 \%$ para todo o período estudado, comparado ao CDI médio de $0,97 \%$. Para o subgrupo dos fundos Master a média foi de $0,84 \%$. Já para o primeiro subperíodo de 5 anos, de 2005 a 2009 a média dos fundos de investimento ficou em $0,85 \%$ abaixo da taxa média do CDI de $1,02 \%$. Os fundos Master estiveram mais próximos com uma taxa média de $0,93 \%$. E no último período calculado, de 2010 a 2014, a taxa média dos fundos ficou em $0,66 \%$ contra um CDI médio de $0,74 \%$. O subgrupo de fundos Master por sua vez ficou com uma taxa média de $0,79 \%$, resultado acima da taxa média do CDI e do consolidado do grupo (tabela 3).

Vale ressaltar que os fundos de investimento de previdência renda fixa como grupo não conseguiu em nenhum período retorno médio acima do CDI. Para o período de janeiro de 2003 a dezembro de 2004 o retorno médio foi $80 \%$ do CDI ou 0,19\% abaixo do índice. De janeiro de 2005 a dezembro de 2009 a distância foi menor, provavelmente influenciado pela crise mundial do biênio de 2008/2009. Ficou em $83 \%$ do CDI ou $0,17 \%$ a menos que o CDI. E, por último, no período de janeiro de 2010 a dezembro de 2014, obtivemos a menor diferença. Os fundos renderam $89 \%$ do CDI ou apenas $0,08 \%$ menos.

Já o retorno médio dos fundos do subgrupo Master se comportou de maneira diversa dos demais fundos. Para o período de janeiro de 2003 a dezembro de 2014 obteve um retorno médio de $87 \%$ do CDI ou $0,13 \%$ abaixo do índice. De janeiro de 2005 a dezembro de 2009 a distância foi bem menor, apesar da crise mundial do biênio de 2008/2009. Ficou em 91\% do CDI ou 0,09\% a menos que o CDI. E, por último, no período de janeiro de 2010 a dezembro de 2014, os fundos Master conseguiram superar o indicador. Os fundos renderam em média 107\% do CDI ou $0,05 \%$ acima.

Para o teste de Kolmogorov-Smirnov, dos 382 fundos testados através do uso do teste para a distribuição normal, com nível de significância de 5\%, 190 fundos rejeitaram a hipótese nula, concluindo que a distribuição de retornos não é normal. 
Os testes para o indicadores CDI, IRF-M e o IMA-B também rejeitaram a hipótese de normalidade.

Fundos $\quad$ Master Ex-Master CDI

\begin{tabular}{|c|c|c|c|c|}
\hline & Funaos & Master & -Master & $C D I$ \\
\hline & \multicolumn{4}{|c|}{ Período: Janeiro de 2003 a Dezembro de 2014} \\
\hline Média & $0,78 \%$ & $0,84 \%$ & $0,77 \%$ & $0,97 \%$ \\
\hline Mediana & $0,74 \%$ & $0,82 \%$ & $0,73 \%$ & $0,88 \%$ \\
\hline Desvio Padrão & $0,78 \%$ & $0,73 \%$ & $0,78 \%$ & $0,32 \%$ \\
\hline Mínimo & $-13,04 \%$ & $-7,54 \%$ & $-13,04 \%$ & $0,45 \%$ \\
\hline \multirow[t]{2}{*}{ Máximo } & $12,50 \%$ & $7,50 \%$ & $12,50 \%$ & $1,98 \%$ \\
\hline & \multicolumn{4}{|c|}{ Periodo: Janeiro de 2005 a Dezembro de 2009} \\
\hline Média & $0,85 \%$ & $0,93 \%$ & $0,84 \%$ & $1,02 \%$ \\
\hline Mediana & $0,83 \%$ & $0,91 \%$ & $0,82 \%$ & $0,97 \%$ \\
\hline Desvio Padrão & $0,66 \%$ & $0,73 \%$ & $0,65 \%$ & $0,25 \%$ \\
\hline Mínimo & $-9,21 \%$ & $-7,54 \%$ & $-9,21 \%$ & $0,63 \%$ \\
\hline \multirow[t]{2}{*}{ Máximo } & $12,50 \%$ & $7,12 \%$ & $12,50 \%$ & $1,58 \%$ \\
\hline & \multicolumn{4}{|c|}{ Período: Janeiro de 2010 a Dezembro de 2014} \\
\hline Média & $0,66 \%$ & $0,79 \%$ & $0,64 \%$ & $0,74 \%$ \\
\hline Mediana & $0,67 \%$ & $0,80 \%$ & $0,66 \%$ & $0,77 \%$ \\
\hline Desvio Padrão & $0,81 \%$ & $0,72 \%$ & $0,82 \%$ & $0,13 \%$ \\
\hline Mínimo & $-7,93 \%$ & $-7,21 \%$ & $-7,93 \%$ & $0,45 \%$ \\
\hline Máximo & $12,29 \%$ & $7,50 \%$ & $12,29 \%$ & $1,03 \%$ \\
\hline
\end{tabular}

Tabela 3 - Estatística Descritiva das Amostras de Retornos.

Elaborado pelo autor.

Para o estudo da análise de estilo baseada em retornos conforme proposto por Sharpe, os resultados evidenciaram uma clara concentração de ativos indexados ao CDI. Foi analisada a série de retornos médio para o setor consolidado, no período de janeiro de 2003 a dezembro de 2014. Segundo a metodologia, o coeficiente relativo ao CDI possui um peso de $89 \%$ do índice, o relativo ao IRF-M tem 10\% do peso e o relativo ao IMA-B o $1 \%$ restante. Isso claramente não vai de encontro ao objetivo de diversificação necessário à obtenção de renda extra na aposentadoria, conforme descrito no capítulo 3.1. 
Esse padrão se repete com razoável uniformidade dentro da categoria conforme fica evidenciado na tabela 4 , onde temos os pesos dos fatores detalhados pelos principais gestores. Apenas 1 gestor possui um peso para o CDI abaixo de $74 \%$. Mesmo assim é apenas pouco abaixo (69\%). Entretanto, se examinarmos entre os 5 maiores gestores de recursos, o peso mais baixo para o CDI sobe para $82 \%$, bem próximo do peso para o setor consolidado. A média para o CDI para os cinco maiores é de $92 \%$, contra um peso de $89 \%$ para o índice consolidado.

Em relação ao comportamento dos principais gestores estrangeiros em relação aos gestores nacionais, não foram encontrados valores muito discrepantes. A concentração de recursos investidos em ativos indexados ao CDI se repete, sendo que a média de aplicação em ativos indexados à CDI para os gestores estrangeiros ficou um pouco acima dos gestores nacionais, $90 \%$ contra $86 \%$, evidenciando uma menor diversificação, o que impactou também os indicadores de desempenho. Os valores para as medianas também se encontram respectivamente em $89 \%$ para os gestores nacionais e $92 \%$ para os gestores estrangeiros. O desvio padrão para todas as amostras se mostra relativamente uniforme, sendo de $9 \%$ para o conjunto dos gestores, de $9 \%$ para os gestores nacionais e de $8 \%$ para os gestores estrangeiros.

Com o resultado de que o fator CDI responde por quase toda a variação do retorno do setor, o próximo passo foi efetuar um estudo de regressão no intuito de avaliar se a inclusão das variáveis IRF-M e IMA-B ajudavam a melhorar a explicação da série de retornos dos fundos de investimento de previdência renda fixa, justificando a montagem de um índice benchmark para avaliar o desempenho da categoria. A escolha dos indicadores IRF-M e IMA-B, conforme descrito anteriormente, advém da sua maior significância econômica relativa dentre os índices disponíveis no mercado de renda fixa brasileiro. 


\begin{tabular}{l|l} 
Gestor1 & Alfa \\
Gestor2 & Banco do Brasil \\
Gestor3 & BNP Paribas \\
Gestor4 & Bradesco \\
Gestor5 & Caixa Econômica Federal \\
Gestor6 & HSBC \\
Gestor7 & Icatu \\
Gestor8 & Itaú \\
Gestor9 & JP Morgan \\
Gestor10 & Mapfre \\
Gestor11 & Metlife \\
Gestor12 & Porto Seguro \\
Gestor13 & Safra \\
Gestor14 & Santander \\
Gestor15 & Sicredi
\end{tabular}

\begin{tabular}{cccc}
\multicolumn{3}{c}{ Peso dos Fatores } & \\
\cline { 1 - 2 } CDI & IRF-M & IMA-B & Volume \\
0,74 & 0,25 & 0,01 & $0 \%$ \\
0,89 & 0,06 & 0,05 & $27 \%$ \\
0,75 & 0,21 & 0,04 & $0 \%$ \\
0,90 & 0,10 & 0,00 & $29 \%$ \\
0,82 & 0,17 & 0,01 & $6 \%$ \\
0,94 & 0,06 & 0,00 & \\
0,69 & 0,16 & 0,15 & \\
1,00 & 0,00 & 0,00 & $25 \%$ \\
0,93 & 0,00 & 0,07 & $0 \%$ \\
0,88 & 0,00 & 0,12 & $0 \%$ \\
0,92 & 0,00 & 0,08 & $0 \%$ \\
0,85 & 0,10 & 0,05 & \\
0,90 & 0,09 & 0,02 & \\
0,99 & 0,00 & 0,01 & $6 \%$ \\
0,91 & 0,00 & 0,09 & $0 \%$
\end{tabular}

Média

$0,87 \quad 0,08 \quad 0,05$

$0,90 \quad 0,06 \quad 0,04$

Mediana

$0,09 \quad 0,08$

0,05

Média 5 maiores

$0,92 \quad 0,07 \quad 0,01$

Mediana 5 maiores

0,90

0,06

0,01

0,08

0,07

0,02

Média Gestores Nacionais

0,86

0,10

0,04

0,89

0,10

0,02

Desvio padrão Gestores Nacionais

0,09

0,08

0,05

Média Gestores Estrangeiros

0,90

0,05

0,05

0,92

0,00

0,05

Desvio padrão Gestores Estrangeiros

0,08

0,08

0,05

Tabela 4 - Análise de Estilo Baseada em Retornos - Principais Gestores. Elaborado pelo autor.

Foram realizadas 2 regressões com o auxílio do software estatístico SPSS versão 22. A primeira delas adotou um modelo com apenas um fator, no caso usamos o CDI. O modelo obteve um $\mathrm{R}^{2}$ de 0,76 e um $\mathrm{R}^{2}$ ajustado também de 0,76. O teste de Durbin-Watson teve como resposta o valor de 1,62 e o erro-padrão da estimativa ficou em 0,0016 , conforme está demonstrado no quadro 1 a seguir. 


\begin{tabular}{|l|r|r|r|r|r|}
\hline Modelo & $\mathrm{R}$ & $\mathrm{R}$ quadrado & \multicolumn{1}{c|}{$\begin{array}{c}\text { R quadrado } \\
\text { ajustado }\end{array}$} & $\begin{array}{c}\text { Erro padrão da } \\
\text { estimativa }\end{array}$ & Durbin-Watson \\
\hline $\mathrm{CDI}$ &, $873^{\mathrm{a}}$ &, 762 &, 760 &, 001594748 & 1,620 \\
\hline
\end{tabular}
a. Preditores: (Constante), CDI
b. Variável Dependente: Fundos

Quadro 1 - Resumo do modelo de um fator - CDI.

Elaborado pelo autor com auxílio do SPSS.

O coeficiente do modelo ficou em 0,874 com uma estatística t de 21,3, conforme quadro 2 abaixo

\begin{tabular}{|c|c|c|c|c|c|c|}
\hline \multirow{2}{*}{\multicolumn{2}{|c|}{ Modelo }} & \multicolumn{2}{|c|}{ Coeficientes não padronizados } & \multirow{2}{*}{$\begin{array}{l}\begin{array}{c}\text { Coeficientes } \\
\text { padronizado }\end{array} \\
\text { Beta }\end{array}$} & \multirow[b]{2}{*}{$\mathrm{t}$} & \multirow[b]{2}{*}{ Sig. } \\
\hline & & B & Erro Padrão & & & \\
\hline & (Constante) & ,001 &, 000 & & 2,627 &, 010 \\
\hline & CDI & ,874 &, 041 & ,873 & 21,295 &, 000 \\
\hline
\end{tabular}

a. Variável Dependente: Fundos

Quadro 2 - Coeficientes do modelo de um fator - CDI.

Elaborado pelo autor com auxílio do SPSS.

Quando foram adicionadas as variáveis IRF-M e o IMA-B o modelo não apresentou uma melhora significativa no seu poder explicativo conforme se evidencia no quadro seguinte. $\mathrm{O} \mathrm{R}^{2}$ caiu para 0,73 com $\mathrm{R}^{2}$ ajustado também em 0,73. Não houve alteração significativa do resultado do Durbin-Watson.

\begin{tabular}{|l|r|r|r|r|r|}
\hline Modelo & $\mathrm{R}$ & $\mathrm{R}$ quadrado & \multicolumn{1}{c|}{$\begin{array}{c}\text { R quadrado } \\
\text { ajustado }\end{array}$} & \multicolumn{1}{c|}{$\begin{array}{c}\text { Erro padrão da } \\
\text { estimativa }\end{array}$} & Durbin-Watson \\
\hline 1 &, $859^{\mathrm{a}}$ &, 738 &, 732 &, 001273309 & 1,617 \\
\hline
\end{tabular}

a. Preditores: (Constante), IMAB, CDI, IRFM

b. Variável Dependente: Fundos

Quadro 3 - Resumo do modelo de três fatores - CDI, IRF-M e IMA-B.

Elaborado pelo autor com auxílio do SPSS.

Os coeficientes do modelo são 0,67 $(13,97)$ para o CDI, $0,05(2,08)$ para o IRF-M e 0,02 (2,92) para o IMA-B. Por conta disso, não parece haver uma vantagem clara em se despender energia na elaboração de um índice benchmark para o setor. 


\begin{tabular}{|c|c|c|c|c|c|c|}
\hline \multirow{2}{*}{\multicolumn{2}{|c|}{ Modelo }} & \multicolumn{2}{|c|}{ Coeficientes não padronizados } & \multirow{2}{*}{$\begin{array}{c}\begin{array}{c}\text { Coeficientes } \\
\text { padronizados }\end{array} \\
\text { Beta }\end{array}$} & \multirow[b]{2}{*}{$\mathrm{t}$} & \multirow[b]{2}{*}{ Sig. } \\
\hline & & $\mathrm{B}$ & Erro Padrão & & & \\
\hline \multirow[t]{4}{*}{1} & (Constante) & ,002 &, 000 & & 5,074 &, 000 \\
\hline & CDI & ,668 & ,048 & ,697 & 13,973 & ,000 \\
\hline & IRFM & ,052 & ,025 & ,163 & 2,085 & ,039 \\
\hline & IMAB & ,028 &, 010 & ,214 & 2,920 & ,004 \\
\hline
\end{tabular}

a. Variável Dependente: Fundos

Quadro 4 - Coeficientes do modelo de três fatores - CDI, IRF-M e IMA-B.

Elaborado pelo autor com auxílio do SPSS.

Com os resultados anteriores ficou evidente que o coeficiente relativo ao CDI é extremamente relevante demonstrando que o uso apenas do CDI como benchmark, além de aumentar o poder teórico, por ser reconhecidamente um possível representante da taxa de juros livre de risco em moeda nacional, não perde relevância como benchmark nos moldes de Blake, Elton e Gruber (1993). Portanto, optou-se no trabalho por adotar, na escolha de benchmark, metodologia de modelo de um fator usando o CDI.

Para a análise de desempenho, tendo em vista que os fundos não têm permissão para manter exposição com risco em moeda estrangeira ou renda variável e além disso, não admitem alavancagem, optou-se por adotar no estudo a avaliação pelo Índice de Sharpe Histórico, já que o uso de outros métodos é apenas necessário quando a série de dados possui alguma exposição ao mercado de renda variável ou a derivativos, notadamente a opções.

Para o estudo do Índice de Sharpe Histórico foram usados três períodos de retornos, conforme relatado anteriormente. No primeiro período que vai de janeiro de 2003 até dezembro de 2014, os fundos foram divididos em dois grupos. No primeiro grupo, com todos os fundos da amostra, a distribuição dos valores do Índice de Sharpe Histórico teve uma média negativa de -0,42, com mediana de $-0,20$ e desvio padrão de 0,68 e pode ser visualizada na figura 6 . A obtenção de Índice de Sharpe negativo evidencia a incapacidade do fundo de superar a taxa de juros livre de risco (CDI). 


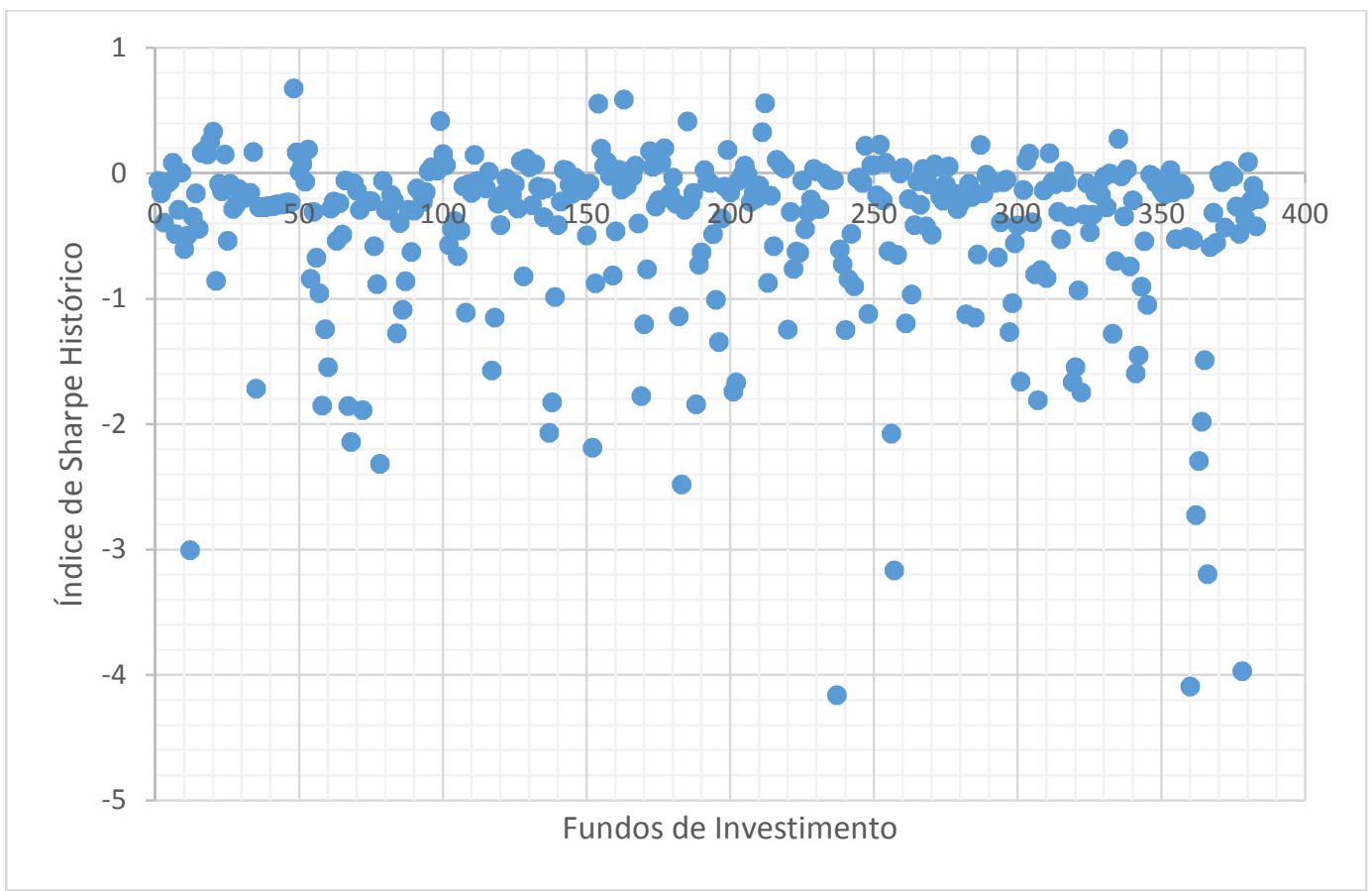

Figura 6 - Índice de Sharpe Histórico dos Fundos de Investimento. Elaborado pelo autor.

Já o segundo grupo, formado apenas de fundos Master, teve um Índice de Sharpe Histórico médio positivo de 0,19 com mediana de 0,15 e desvio padrão de 0,18 conforme a figura 7 .

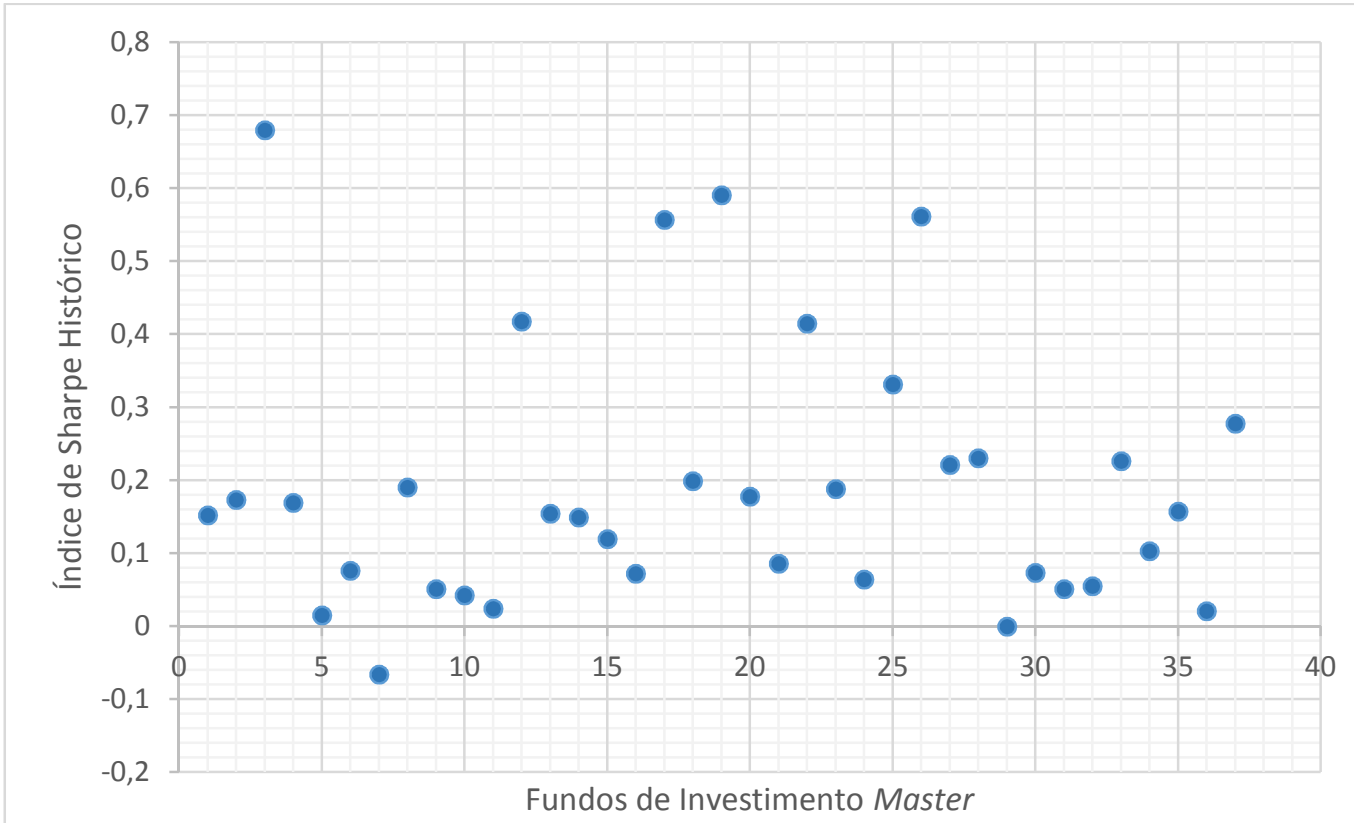

Figura 7 - Índice de Sharpe Histórico dos Fundos Master. Elaborado pelo autor. 
Por último, após a extração dos fundos Master, o grupo que denominaremos por Ex-Master ficou com a distribuição retratada na figura 8. A média para esse subgrupo ficou negativa em -0,49 com mediana em -0,24 e desvio padrão em 0,69.

Não foram obtidos resultados discrepantes nos outros dois subperíodos para a amostra contendo todos os fundos. Para o período de janeiro de 2005 a dezembro de 2009 a média do Índice de Sharpe Histórico ficou negativa em -1,33, com mediana de $-0,55$ e desvio padrão de 2,26. Para o período de janeiro de 2010 a dezembro de 2014 a média do Índice de Sharpe Histórico foi também negativa em $-0,73$, com mediana de $-0,29$ e desvio padrão de 1,77 .

O estudo procurou também apurar se havia diferenças nos Índices de Sharpe dos gestores nacionais e estrangeiros. $\mathrm{O}$ grupo dos nacionais obteve resultados um pouco melhores no subgrupo dos fundos Master. Os gestores dos fundos Master nacionais obtiveram em média um Índice de Sharpe Histórico de 0,21, com mediana de 0,17 e desvio padrão de 0,20 . Já os estrangeiros obtiveram uma média um pouco abaixo de 0,12, com mediana de 0,12 e desvio padrão de 0,08 .

Como os valores do Índice de Sharpe Histórico para os fundos Master indicam excesso de retorno positivo, porém baixo, o próximo passo consiste em testar se a amostra do excesso de retorno dos fundos Master poderia ser estatísticamente significativamente diferente de zero.

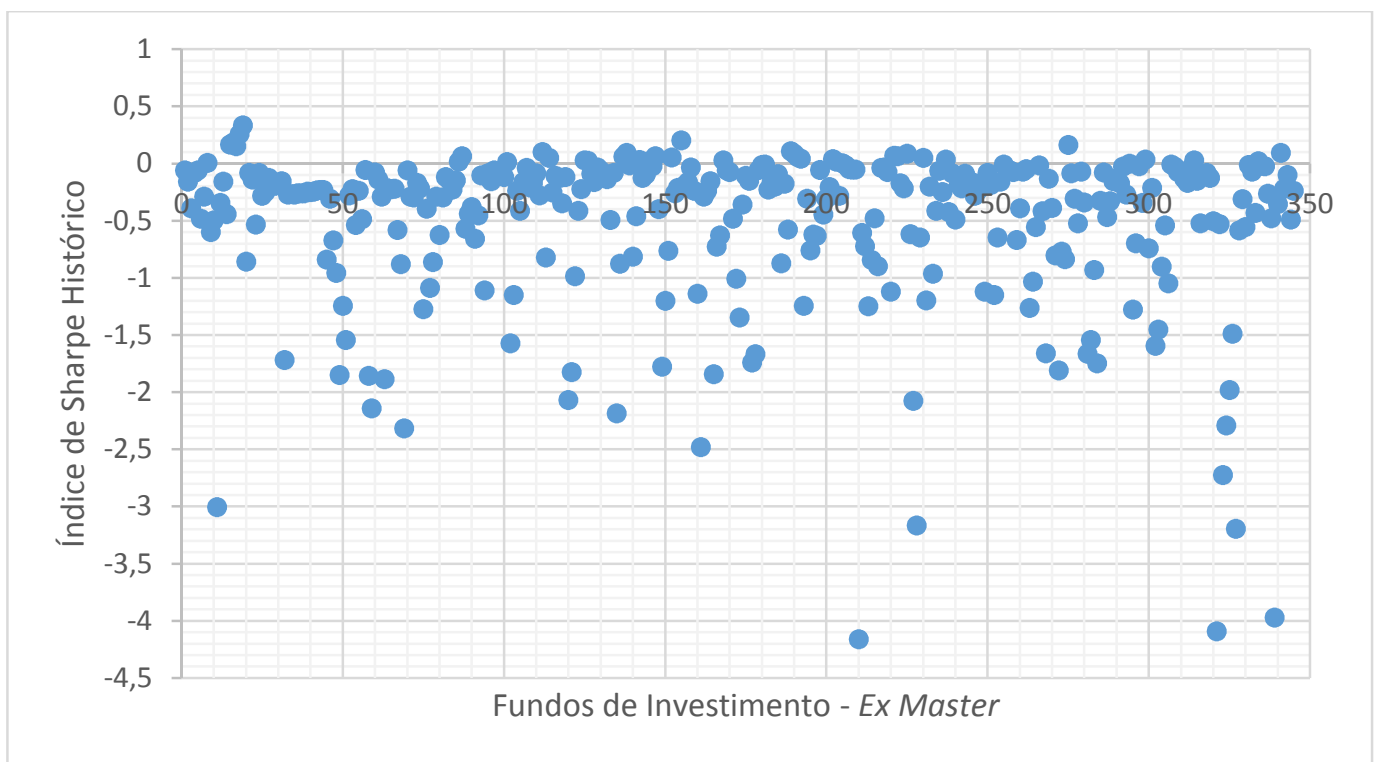

Figura 8 - Índice de Sharpe Histórico dos Fundos Ex Master. Elaborado pelo autor. 
As estatísticas descritivas da série de diferença de retorno consolidada para os fundos Master são: média de 0,15\%, mediana de $0,01 \%$ e desvio padrão de $1,55 \%$. De posse da série de diferenças de retorno aplicou-se o teste de Kolmogorov-Smirnov para averiguar a normalidade da série. O resultado do teste foi que a série teve rejeitada a hipótese de normalidade conforme o quadro 5 abaixo.

\begin{tabular}{|c|c|c|}
\hline \multicolumn{2}{|l|}{ Parâmetros } & Resultados \\
\hline \multicolumn{2}{|l|}{$\mathrm{N}$} & 147 \\
\hline \multirow[t]{3}{*}{ Parâmetros normais ${ }^{\mathrm{a}, \mathrm{b}}$} & Média & 0,00148475 \\
\hline & Mediana & 0,00013525 \\
\hline & Desvio Padrão & 0,01545819 \\
\hline \multicolumn{2}{|l|}{ Estatística de teste } &, 412 \\
\hline \multicolumn{2}{|c|}{ Significância Sig. (2 extremidades) } &, $000^{\mathrm{c}}$ \\
\hline
\end{tabular}
a. A distribuição do teste é Normal.
b. Calculado dos dados.
c. Correção de Significância de Lilliefors.

Quadro 5 - Teste de Kolmogorov-Smirnov para a série de diferenças de retorno vs CDI. Elaborado pelo autor com auxílio do SPSS.

Em vista disso optou-se por aplicar um teste não paramétrico para mediana. Para tanto, aplicou-se o Teste dos Postos de Wilcoxon com a hipótese nula de que a mediana seria igual a zero. Como resultado obtivemos que a hipótese nula foi rejeitada, conferindo significância estatística para a diferença de retornos dos fundos Master, conforme a figura 9.

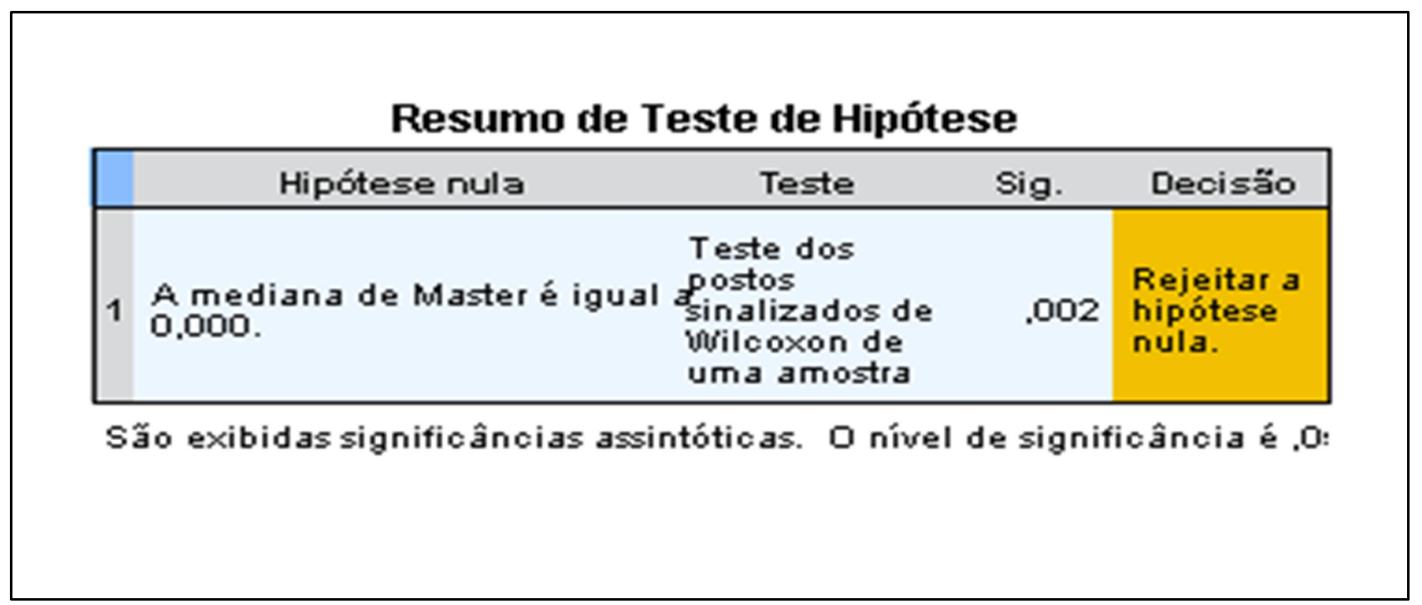

Figura 9 - Resumo de Teste de Hipótese de Wilcoxon.

Elaborado pelo autor com auxílio do SPSS. 
Por último é importante ressaltar a necessidade de cuidado na escolha da amostra. Se o pesquisador optar por privilegiar uma amostra com volume de recursos relevantes dentro da indústria, vai optar por estudar os fundos Master e concluir que os fundos de previdência renda fixa são eficientes no conceito de Sharpe, produzindo um excesso de retorno estatisticamente significativo a $5 \%$. Entretanto se optar por escolher uma amostra com grande quantidade de fundos, em detrimento do volume de ativos, vai chegar a uma conclusão diametralmente oposta, ou seja que os fundos de previdência renda fixa não possuem excesso de retorno estatisticamente significativo e possuem um indicador de Sharpe negativo - o que não se presta a uma avaliação adequada. Ambas as abordagens são robustas e válidas, alertando o estudioso da necessidade de uma análise prévia do enfoque que se gostaria de utilizar e a dificuldade em se valer de ferramentas de análise sem uma contextualização adequada. 


\section{6 \\ Conclusão}

Este trabalho desenvolveu uma análise da indústria de fundos de previdência renda fixa no Brasil, no período de 2003 a 2014, com destaque para a utilização da consagrada metodologia de avaliação de desempenho de Sharpe. A principal motivação de tal pesquisa considera o fato do crescimento expressivo da indústria de fundos de previdência desde 2003.

Diante disso, vislumbrou-se uma oportunidade de exploração desse estudo como ferramenta de auxílio ao poupador na hora de direcionar seus recursos como plano de aposentadoria. Diante da necessidade de geração de renda no período da aposentadoria, a avaliação de desempenho tem papel fundamental e a análise tradicional de escolha da carteira ótima deve ser adaptada considerando as particularidades e restrições distintas, que devem ser avaliadas caso a caso.

O estudo empírico desenvolvido considerou para o período em questão uma amostra de 382 fundos de investimento de previdência renda fixa, que representam aproximadamente $99 \%$ do total de recursos de fundos de previdência em atividade, cujos investimentos totalizavam aproximadamente R \$ 400 bilhões em 2014 .

Blake, Elton e Gruber (1993) argumentam que para se obter uma medida de desempenho, deve-se ter em mente que a seleção do índice de referência (benchmark) deve ser cuidadosa. Para definir qual índice usar, e tendo em vista as limitações da amostra, qual seja, de não poder investir em ativos indexados a renda variável ou a moedas, optou-se por utilizar a Análise de Estilo Baseada em Retornos (SHARPE, 1992) para os indicadores IRF-M, CDI e IMA-B.

Os resultados mostram que o coeficiente relativo ao CDI é extremamente relevante, por ser reconhecidamente um possível representante da taxa de juros livre de risco em moeda nacional. Portanto, optou-se no trabalho por adotar, na escolha de benchmark, metodologia de modelo de um fator usando o CDI.

Os resultados demonstram que os fundos de Previdência Renda Fixa, não conseguiram atingir um resultado satisfatório. Entretanto, o grupo de Fundos 
Master conseguiu uma performance superior aos da categoria, obtendo também um excesso de retorno com significância estatística de 5\%.

Nossos resultados indicam que a totalidade dos grandes gestores de fundos Master consegue obter um bom resultado na parte ativa das carteiras, resultado esse, que contrasta com o obtido em diversos estudos anteriores do gênero. $\mathrm{O}$ interessante sobre o grupo de fundos Master é que, apesar de pouco numeroso (são 38 fundos dentre uma amostra de 382), ele é responsável por cerca de $90 \%$ do volume de recursos do setor. Sendo assim, uma explicação possível para o resultado obtido está associada ao fato de haver extrema concentração de recursos nas mãos de poucos gestores, lhes provendo um maior poder de barganha para composição de suas carteiras.

Entretanto, apesar do bom resultado na parte ativa, devido às altas taxas (taxas de administração e performance) incidentes nos fundos investidores - os feeders, isso não se traduz em bons resultados para os investidores finais, evidenciado pelos resultados insatisfatórios da categoria como um todo. Fica evidente o lado perverso da enorme concentração do setor. Os gestores absorvem, através das taxas cobradas, todo o excesso de retorno gerado nas carteiras.

É importante lembrar que a Teoria Moderna de Portfólio, sugere que todo investidor deve considerar a diversificação para a composição da cesta de fundos de longo prazo. Então, essa concentração em ativos de renda fixa vai trazer alguma insatisfação no futuro, quando a renda da aposentadoria terá de ser gerada. A importância de tais estudos é evidente para ajudar as políticas públicas em um setor extremamente concentrado, como é o setor financeiro no Brasil.

Por fim, cabe destacar que os testes estatísticos mostraram resultados aparentemente contraditórios. Isso pode ser observado pelo fato de que, dependendo do "filtro" que o estudioso escolha, pode-se obter um resultado completamente diferente, apesar de ambos apresentarem robustez teórica. Caso se opte por estudar os fundos Master, o pesquisador concluirá que o setor é eficiente, com todos os principais gestores apresentando capacidade superior de desempenho. Se a investigação incluir a categoria de fundos como um todo, a conclusão será diametralmente oposta, apesar do uso da mesma metodologia de avaliação de desempenho. Fica evidente, portanto, que o uso das ferramentas de análise deve ser precedido de alguma avaliação do ambiente microeconômico em que os fundos estão inseridos e como isso pode vir a afetar os resultados obtidos no estudo. 


\section{Referências bibliográficas}

AMARAL, Tânia Raquel dos Santos. Análise de performance de fundos de investimento em previdência. 2013. 168 p. Dissertação (Mestrado). Universidade de São Paulo, 2013.

ASSOCIAÇÃO BRASILEIRA DAS ENTIDADES DOS MERCADOS FINANCEIROS E DE CAPITAIS - ANBIMA. Boletim de Renda Fixa. Disponível em: $<\mathrm{http}$ //portal.anbima.com.br/informacoes-tecnicas/boletins/rendafixa/Pages/default.aspx>. Acesso em: 05 jan. 2015.

Classificação ANBIMA de Fundos. Disponível em:

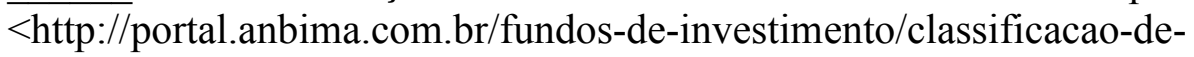
fundos/classificacao-anbima-de-fundos/Pages/classificacao.aspx $>$. Acesso em: 31 jul. 2014.

BELTRÃO, Kaizô Iwakami et al. Análise da Estrutura da Previdência Privada Brasileira: Evolução do Aparato Legal. Texto para Discussão IPEA, v. 1043, p. 1-30, 2004.

BERTUCCI, Luiz Alberto; SOUZA, Flávio Henrique Ribeiro De; FÉLIX, Luiz Fernando Fortes. Gerenciamento de risco de fundos de pensão no Brasil: alocação estratégica ou simples foco na meta atuarial?. Revista Economia \& Gestão, v. 6, n. 13, p. 17, 2006.

BLAKE, Christopher R.; ELTON, Edwin J.; GRUBER, Martin J. The performance of bond mutual funds. Journal of Business, v. 66, n. 3, p. 371-403, 1993.

BRASIL. Decreto $\mathrm{n}^{\circ} 4.682$ de 24 de janeiro de 1923. Disponível em $<$ http://www.planalto.gov.br/ccivil_03/decreto/Historicos/DPL/DPL4682.htm> Acesso em: 31 jul. 2014.

. Lei $\mathrm{n}^{\mathrm{o}} 3.807$ de 26 de agosto de 1960. Disponível em

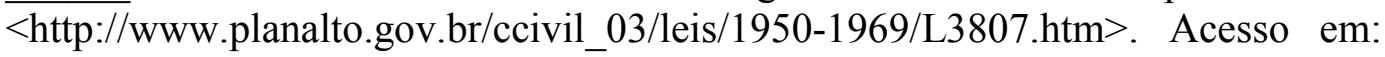
31 jul. 2014.

Decreto-Lei $\mathrm{n}^{\mathrm{o}} 73$ de 21 de novembro de 1966. Disponível em $<$ http://www.planalto.gov.br/ccivil_03/decreto-lei/del0073.htm>. Acesso em: 31 jul. 2014.

Lei $\mathrm{n}^{\mathrm{o}} 5.316$ de 14 de setembro de 1967. Disponível em <http://www.planalto.gov.br/ccivil_03/leis/1950-1969/L5316.htm> Acesso em: 31 jul. 2014. 
Lei $\mathrm{n}^{\mathrm{o}} 6.435$ de 15 de julho de 1977 Disponível em

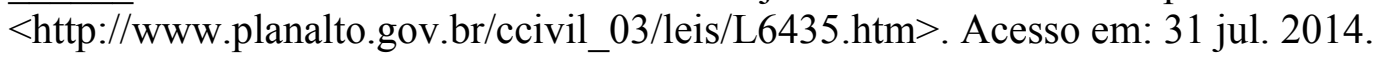

. Lei $\mathrm{n}^{\mathrm{o}} 8.212$ de 24 de julho de 1991. Disponível em

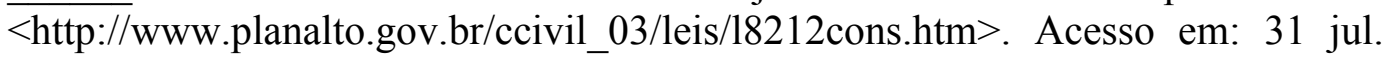
2014.

Lei $\mathrm{n}^{\mathrm{o}} 8.213$ de 24 de julho de 1991. Disponível em

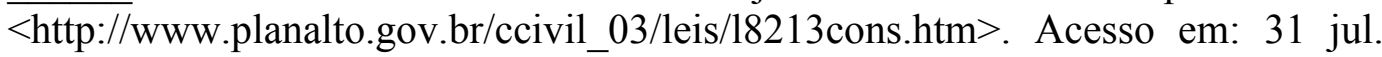
2014.

Emenda Constitucional no 20 de 15 de dezembro de 1998. Disponível em $\overline{<\mathrm{http}: / / w w w . p l a n a l t o . g o v . b r / c c i v i l \_03 / c o n s t i t u i c a o / E m e n d a s / E m c / e m c 20 . h t m>. ~}$ Acesso em: 31 jul. 2014.

Decreto $\mathrm{n}^{\mathrm{o}} 3.048$ de 6 de maio de 1999. Disponível em

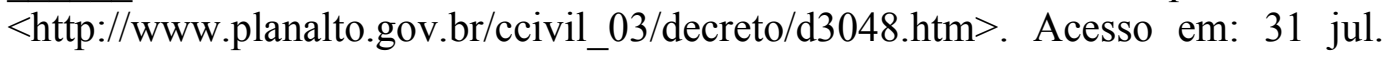
2014.

Lei Complementar $\mathrm{n}^{\circ} 109$ de 29 de maio de 2001 Disponível em $<$ http://www.planalto.gov.br/ccivil_03/leis/LCP/Lcp109.htm>. Acesso em: 31 jul. 2014.

Lei $\mathrm{n}^{\mathrm{o}} 12.618$ de 30 de abril de 2012 Disponível em

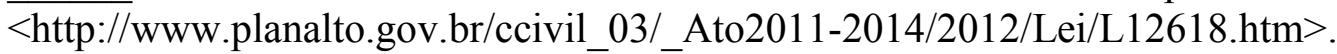
Acesso em: 31 jul. 2014.

CAMPBELL, John Y.; VICEIRA, Luis M. Strategic Asset Allocation: Portfolio Choice for Long-term Investors. 1. ed. Nova Iorque: Oxford University Press, 2002. $274 \mathrm{p}$.

CAPORIN, Massimiliano et al. A survey on the four families of performance measures. Journal of Economic Surveys, v. 28, n. 5, p. 917-942, 2014.

CARDOSO, Alexandre Cabral. Análise de Persistência de Performance nos Fundos de Previdência Complementar entre 2001 e 2004. 2006. 96 p. Dissertação (Mestrado). Faculdades IBMEC, 2006.

CHAN, Louis K. C.; CHEN, Hsiu-Lang; LAKONISHOK, Josef. On mutual fund investment styles. Review of Financial Studies, v. 15, n. 5, p. 1407-1437, 2002.

CHEN, Joseph et al. Does Fund Size Erode Mutual Fund Performance? The Role of Liquidity and Organization. American Economic Review, v. 94, n. 5, p. 1276 1302, 2004.

CICCOTELLO, Conrad S.; GRANT, C. Terry. Information Pricing: The Evidence From Equity Mutual Funds. Financial Review, v. 31, n. 2, p. 365-380, 1996. 
COWLES, Alfred. Can stock market forecasters forecast? Econometrica: Journal of the Econometric Society, p. 309-324, 1933.

DETZLER, Miranda Lam. The Performance of Global Bond Mutual Funds. SSRN Electronic Journal ,1997. Disponível em: <http://dx.doi.org/10.2139/ssrn.62>. Acesso em: 31 jul. 2014.

DRAGO, Alessandro Del; BRITO, Ricardo D. O. Modelo de múltiplos fatores com marketing timing aplicado a fundos de investimentos multimercados macro no Brasil. In: 12 ${ }^{\mathbf{0}}$ Encontro Brasileiro de Finanças - SBFIN, São Paulo, jul. 2012.

ELTON, Edwin J.; GRUBER, Martin J.; BLAKE, Christopher R. The Persistence of Risk-Adjusted Mutual Fund Performance. The Journal of Business, v. 69, n. 2, p. 133-157, 1996.

FAMA, Eugene F. Multiperiod Consumption-Investment Decisions. The American Economic Review, v. 60, n. 1, p. 163-174, 1970.

; SCHWERT, G. William. Asset returns and inflation. Journal of Financial Economics, v. 5, p. 115-146, 1977.

HODGES, Stewart. A generalization of the Sharpe ratio and its applications to valuation bounds and risk measures. Preprint, Financial Options Center of the University of Warwick, In: The Newton Institute, Cambridge, October 1998, p. 1-17, 1998.

HWANG, Soosung.; SATCHELL, Stephen. Tracking error: ex-ante versus ex-post measures. 2001. Journal of Asset Management, v. 2, n. 3, p. 241-246, 2001,

JENSEN, Michael C. Optimal utilization of market forecasts and the evaluation of investment performance. In: Mathematical Methods in Finance, 1. ed., Nova Iorque: North Holland Publishing Co., 1972. 665 p.

The Performance of Mutual Funds in the Period 1945-1964. Journal of Finance, v. 23, n. 2, p. 389-416, maio 1967.

JORION, Phillipe. Portfolio optimization with tracking-error constraints. Financial Analysts Journal, v. 59, n. 5, p. 70-82, 2003.

KEATING, Con; SHADWICK, William F. A universal performance measure. Journal of Performance Measurement, v. 6, n. 3, p. 59-84, 2002a.

An introduction to omega. AIMA Newsletter, p. 1-15, 2002 b.

KHORANA, Ajay; SERVAES, Henri; TUFANO, Peter. Explaining the size of the mutual fund industry around the world. Journal of Financial Economics, v. 78, p. 145-185, 2005. 
KIM, Moon; SHUKLA, Ravi; TOMAS, Michael. Mutual Fund Objective Misclassification. Journal of Economics and Business, v. 52, n. 4, p. 309-323, 2000 .

LARSEN, G.; RESNICK, B. Empirical Insights on Indexing: How Capitalization, Stratification and Weighting Can Affect Tracking Error. Journal of Portfolio Management, v. 25, n. 1, p. 51, 1998.

LEAL, Ricardo Pereira Câmara; CARVALHAL DA SILVA, André Luiz. The Development of the Brazilian Bond Market. SSRN Electronic Journal, 2006. Disponível em: $<$ http://www.ssrn.com/abstract=935268>. Acesso em: 31 jul. 2014.

LIMA, Adilson Celestino De. Desempenho dos fundos de investimento do tipo previdência privada e sua sensibilidade à variação da taxa de juros. Revista de Administração Mackenzie, v. 7, n. 2, p. 61-77, 2006.

LO, Andrew W. The statistics of Sharpe ratios. Financial Analysts Journal, v. 58, n. 4, p. 36-52, 2002.

MAHDAVI, Mahnaz. Risk-adjusted return when returns are not normally distributed: Adjusted Sharpe ratio. The Journal of Alternative Investments, v. 6, n. 4, p. 47-57, jan. 2004.

MARKOWITZ, Harry. Portfolio selection. The Journal of Finance, v. 7, n. 1, p. 77-91, 1952.

MAYERS, David. Nonmarketable Assets and Capital Market Equilibrium under Uncertainty, In: Michael C. Jensen Studies in the Theory of Capital Markets, Nova Iorque: Praeger, 1972.

MERTON, Robert C. An Intertemporal Capital Asset Pricing Model. Econometrica: Journal of the Econometric Society, v. 41, n. 5, p. 867-887, 1973.

Lifetime Portfolio Selection Under Uncertainty: the Continuous-Time Case. The Review of Economics and Statistics, v. 51, n. 3, p. 247-257, 1969.

Optimum Consumption and Portfolio Rules in a Continuous-Time Model. Journal of Economic Theory, v. 3, p. 373-413, 1971.

MODIGLIANI, Franco; MODIGLIANI, Leah. Risk-Adjusted Performance. The Journal of Portfolio Management, v. 23, n. 2, p. 45-54, 1997.

; SUTCH, Richard. Innovations in Interest Rate Policy. The American Economic Review, v. 56, p. 178-197, 1966.

MOSSIN, Jan. Optimal Multiperiod Portfolio Policies. The Journal of Business, v. 41, n. 2, p. 215-229, 1968. 
MUNHÓS, José Luiz. Previdência social: um estudo comprado do modelo brasileiro de previdência social pública e do modelo chileno de previdência. 2007. Tese (Doutorado). PUC/SP, 2007.

ODA, André Luiz. Desempenho de fundos de ações - Análise de persistência de performance dos fundos de ações brasileiros. 1. ed. São Paulo: Saint Paul Editora, 2007. 164 p.

PORDES, Anthony. Averting the old age crisis: Policies to protect the old and promote growth. World Bank. Nova Iorque: Oxford University Press, 1994. 402 p.

RAZALI, Nornadiah Mod; WAH, Yap Bee. Power comparisons of shapiro-wilk, kolmogorov-smirnov, lilliefors and anderson-darling tests. Journal of Statistical Modeling and Analytics, v. 2, n. 1, p. 21-33, 2011.

ROLL, Richard. A Mean Variance Analysis of Tracking Error. The Journal of Portfolio Management, v. 18, n. 4, p. 13-22, 1992.

RUBINSTEIN, Mark. The strong case for the generalized logarithmic utility model as the premier model of financial market. Research Program in Finance. WP $n$. $34,1975$.

RUDOLF, Markus; WOLTER, Hans-Jürgen; ZIMMERMANN, Heinz. A linear model for tracking error minimization. Journal of Banking \& Finance, v. 23, n. 1, p. 85-103, 1999.

SAMUELSON, Paul A. Lifetime Portfolio Selection by Dynamic Stochastic Programming. Review of Economics and Statistics, v. 51, n. 3, p. 239-246, 1969.

p. 1-6, 1963.

Risk and Uncertainty: A Fallacy of Large Numbers. Scientia, v. 6th series,

SANVICENTE, Antônio Zorato; FRANÇA, Everaldo Guedes de Azevedo. Desempenho de fundos de ações no mercado brasileiro: 1984/1985. Revista de Administração, v. 24, n. 3, p. 3-10, 1989.

SAVOIA, José Roberto Ferreira. Os fundos de aplicação de curto prazo: uma análise de desempenho. Dissertação (Mestrado). FEA-USP. São Paulo, 1990.

SECURATO, José Roberto. et al. Avaliação de Desempenho de Fundos de Investimento. Guia de Fundos de Renda Fixa da FIA-FEA/USP. São Paulo, 1999.

SECURATO, José Roberto; CHÁRA, Alexandre Noburu; SENGER, Maria Carlota Morandin. Análise do perfil dos fundos de renda fixa do mercado brasileiro. Seminários em Administração, 1998. p. 1-9.

SHARPE, William F. Asset Allocation: Management Style and Performance Measurement. Journal of Portfolio Management, v. 18, p. 7-19, 1992. 

$138,1966$.

Mutual fund performance. The Journal of Business, v. 39, n. 1, p. 119 The sharpe ratio. The Journal of Portfolio Management, v. 21, n. 1, p. 49-58, 1994.

SILVA, Fabiana Lopes Da. Impacto do risco de longevidade em planos de previdência complementar. 2010. Tese (Doutorado). Universidade de São Paulo, 2010.

STIGLITZ, John E. Review of Some Aspects of Theory of Risk Bearing by K. J. Arrow. Econometrica, v.38, 1970.

SUPERINTENDÊNCIA DE SEGUROS PRIVADOS - SUSEP. Resolução CNSP $\mathrm{n}^{\circ} \quad 140$ de 27 de dezembro de 2005. Disponível em: $<$ http://www2.susep.gov.br/bibliotecaweb/biblioteca.aspx $\geq$. Acesso em: 02 out. 2014.

.Circular SUSEP $\mathrm{n}^{\mathrm{o}} 338$ de 30 de janeiro de 2007. Disponível em: $<$ http://www2.susep.gov.br/bibliotecaweb/biblioteca.aspx $\geq$. Acesso em: 02 out. 2014.

SWINKELS, Laurens; SLUIS, Pieter J. Van Der. Return-based style analysis with time-varying exposures. The European Journal of Finance, v. 12, n. 6-7, p. 529$552,2006$.

TREYNOR, Jack L. How to rate management of investment funds. Harvard Business Review, v. 43, p. 63-75, 1965.

VARGA, Gyorgy. Indicadores de investimento e de seleção de fundos. In: Gyorgy Varga; Ricardo Leal. (Org.). Gestão de Investimentos e Fundos. Rio de Janeiro: Keyword Editora, v. 1, p. 369-404. 2006.

VILELLA, Paulo Alvarez; LEAL, Ricardo Pereira Câmara. O Desempenho de Fundos de Renda Fixa e o Índice de Renda Fixa de Mercado (IRF-M). RAEeletrônica, v. 7, n. 1, 2008.

VITAL, Sebastião Marcos. Fundos de Investimento: medida de seu desempenho. Revista Brasileira de Economia, v. 27, n. 3, p. 19-64, 1973.

YANG, Alice et al. Comparação entre Fundos Previdenciários e Não Previdenciários. EESP: Estudos em Finanças: Investimentos II, p. 59-75, 2010.

ZAKAMOULINE, Valeri; KOEKEBAKKER, Steen. Portfolio performance evaluation with generalized Sharpe ratios: Beyond the mean and variance. Journal of Banking and Finance, v. 33, n. 7, p. 1242-1254, 2009. 